\title{
The effects of human immunoglobulin $G$ on enhancing tissue protection and neurobehavioral recovery after traumatic cervical spinal cord injury are mediated through the neurovascular unit
}

\author{
Jonathon Chon Teng Chio 1,2,4, Jian Wang ${ }^{1}$, Anna Badner ${ }^{3}$, James Hong ${ }^{1,2,4}$, Vithushan Surendran ${ }^{5}$ and
} Michael G. Fehlings $s^{1,2,4,5,6,7^{*}}$ (D)

\begin{abstract}
Background: Spinal cord injury (SCI) is a condition with few effective treatment options. The blood-spinal cord barrier consists of pericytes, astrocytes, and endothelial cells, which are collectively termed the neurovascular unit. These cells support spinal cord homeostasis by expressing tight junction proteins. Physical trauma to the spinal cord disrupts the barrier, which leads to neuroinflammation by facilitating immune cell migration to the damaged site in a process involving immune cell adhesion. Immunosuppressive strategies, including methylprednisolone (MPSS), have been investigated to treat SCl. However, despite some success, MPSS has the potential to increase a patient's susceptibility to wound infection and impaired wound healing. Hence, immunomodulation may be a more attractive approach than immunosuppression. Approved for modulating neuroinflammation in certain disorders, including Guillain-Barre syndrome, intravenous administration of human immunoglobulin $\mathrm{G}$ (hlgG) has shown promise in the setting of experimental $\mathrm{SCl}$, though the optimal dose and mechanism of action remain undetermined.
\end{abstract}

Methods: Female adult Wistar rats were subjected to moderate-severe clip compression injury (35 g) at the C7-T1 level and randomized to receive a single intravenous (IV) bolus of hlgG $(0.02,0.2,0.4,1,2 \mathrm{~g} / \mathrm{kg})$, MPSS $(0.03 \mathrm{~g} / \mathrm{kg})$, or control buffer at $15 \mathrm{~min}$ post-SCl. At $24 \mathrm{~h}$ and 6 weeks post-SCl, molecular, histological, and neurobehavioral effects of hlgG were analyzed.

Results: At $24 \mathrm{~h}$ post-injury, human immunoglobulin G co-localized with spinal cord pericytes, astrocytes, and vessels. hlgG (2 g/kg) protected the spinal cord neurovasculature after SCl by increasing tight junction protein expression and reducing inflammatory enzyme expression. Improvements in vascular integrity were associated with changes in spinal cord inflammation. Interestingly, hlgG (2 g/kg) increased serum expression of inflammatory cytokines and co-localized (without decreasing protein expression) with spinal cord vascular cell adhesion molecule-1, a protein used by immune cells to enter into inflamed tissue. Acute molecular benefits of hlgG $(2 \mathrm{~g} / \mathrm{kg})$ led to greater tissue preservation, functional blood flow, and neurobehavioral recovery at 6 weeks post-SCl. Importantly, the effects of hlgG ( $2 \mathrm{~g} / \mathrm{kg})$ were superior to control buffer and hlgG $(0.4 \mathrm{~g} / \mathrm{kg})$, and comparable with MPSS $(0.03 \mathrm{~g} / \mathrm{kg})$.

(Continued on next page)

\footnotetext{
*Correspondence: michael.fehlings@uhn.ca

'Department of Genetics and Development, Krembil Research Institute,

University Health Network, Krembil Discovery Tower, 60 Leonard Avenue,

7KD-430, Toronto, Ontario M5T 258, Canada

${ }^{2}$ Institute of Medical Science, University of Toronto, Toronto, Ontario, Canada

Full list of author information is available at the end of the article
}

(C) The Author(s). 2019 Open Access This article is distributed under the terms of the Creative Commons Attribution 4.0 International License (http://creativecommons.org/licenses/by/4.0/), which permits unrestricted use, distribution, and reproduction in any medium, provided you give appropriate credit to the original author(s) and the source, provide a link to the Creative Commons license, and indicate if changes were made. The Creative Commons Public Domain Dedication waiver (http://creativecommons.org/publicdomain/zero/1.0/) applies to the data made available in this article, unless otherwise stated. 
(Continued from previous page)

Conclusions: $\mathrm{hlgG}(2 \mathrm{~g} / \mathrm{kg})$ is a promising therapeutic approach to mitigate secondary pathology in $\mathrm{SCl}$ through antagonizing immune cell infiltration at the level of the neurovascular unit.

Keywords: Spinal cord injury, Human immunoglobulin G, Neuroinflammation, Immunomodulation, Dose-response, Neurovascular unit

\section{Background}

Despite significant medical advances, spinal cord injury (SCI) continues to be a debilitating neurological condition. SCI pathophysiology is divided into two stages [1], beginning with damage from the initial physical injury causing an immediate structural disturbance. This initial physical insult is exacerbated during the second stage by infiltration of immune cells into the injured spinal cord (hereby referred to as neuroinflammation), which is associated with damage to the blood-spinal cord barrier (BSCB) and loss of tight junction (TJ) proteins. To target neuroinflammation, systemic immunosuppressive strategies, including methylprednisolone (MPSS), have been successfully used following the initial physical insult to improve functional outcomes in pre-clinical and clinical SCI studies [2-6]. However, recent research suggests that these therapies may be suboptimal, as patients develop systemic immune deficiency $[7,8]$ and the beneficial aspects of neuroinflammation, necessary for regeneration and remyelination, become limited [9]. Therefore, immunomodulation is deemed a more attractive approach than systemic immunosuppression to target the neuroinflammatory response.

Human immunoglobulin G (hIgG) is approved by the Food and Drug Administration to treat both immunodeficiency and autoimmune conditions $[10,11]$. Despite the wide use of hIgG in the clinic, the mechanism of action remains uncertain [10]. Numerous studies have reported a diverse array of effects, including $\mathrm{B}$ and $\mathrm{T}$ cell trafficking, neutralization of autoantibodies, modulation of the complement cascade, and cytokine production. These effects are mediated by both $F_{c}$ and $F_{(a b) 2}$ components of hIgG. Although previous research has demonstrated hIgGinduced increases in functional recovery by reducing neuroinflammation in pre-clinical models of SCI, the method of administration [12] and models used have not been clinically relevant $[13,14]$. Further, it is unknown whether the beneficial effects of hIgG following $\mathrm{SCI}$ are dosedependent. Given these gaps in knowledge, we used a wellcharacterized clip compression-contusion SCI model with a minimally invasive administration method to identify the optimal dose of hIgG administration and examined the immunomodulatory effects on the immune response after SCI. We hypothesized that early treatment with hIgG would immunomodulate spinal cord inflammatory cell populations after traumatic cervical SCI, in part by enhancing the integrity of the BSCB. This work builds on our prior publication [15] by demonstrating that high-dose hIgG $(2 \mathrm{~g} / \mathrm{kg})$ is significantly more effective than our previously reported hIgG dose $(0.4 \mathrm{~g} / \mathrm{kg})$ at modulating the acute neuroinflammatory response. Further, the present study shows that hIgG has protective effects that are mediated through the spinal cord neurovascular unit.

\section{Materials and methods}

\section{Experimental and control groups}

A total of 124 female adult Wistar rats (250-300 g) from Charles River were used in this study. Of these rats, 52 were used for dose-response studies to investigate the molecular and biochemical changes, 24 to examine the changes in tissue morphology and histology, and 48 to assess the neurobehavioral recovery and tissue preservation. All procedures followed the animal use protocol approved by the Animal Use Committee at the University Health Network. Rats were randomly assigned to sham (receiving laminectomy only) or SCI groups. For rats in the SCI group, a well-characterized model of injury (35-g modified aneurysm clip applied extradurally at the C7-T1 level for 60 seconds (s) to cause a moderate-severe $\mathrm{SCI}$ ) was used $[16,17]$. Animals were given $1 \mathrm{ml}$ of buprenorphine $(0.03$ $\mathrm{mg} / \mathrm{kg}$ ) and $5 \mathrm{ml}$ of saline immediately following surgery. Subsequently, buprenorphine and saline were given twice a day up to 3 and 7 days, respectively.

hIgG $(100 \mathrm{mg} / \mathrm{ml})$ and control buffer were provided by Shire/Baxalta (USA). At 15 min post-SCI, a single bolus of hIgG was intravenously administered at various doses $(0.02 \mathrm{~g} / \mathrm{kg}(n=9), 0.2 \mathrm{~g} / \mathrm{kg}(n=6), 0.4 \mathrm{~g} / \mathrm{kg}(n=12 ; n=6$ for biochemical analysis, 6 for ultrasound and histology), $1 \mathrm{~g} / \mathrm{kg}(n=6), 2 \mathrm{~g} / \mathrm{kg}(n=12 ; n=6$ for biochemical analysis, 6 for ultrasound and histology)). Control buffer ( $n=12 ; n=6$ for biochemical analysis, 6 for ultrasound and histology) or methylprednisolone (MPSS, $0.03 \mathrm{~g} / \mathrm{kg}$ ) $(n=7)$ were injected in an identical fashion as negative and positive controls, respectively. The dosage of MPSS given was based on the reported dosage for human SCI patients [18], whereas dosages of hIgG corresponded to those currently used in the clinic [10]. For all studies, randomization was achieved through prepared lists, with treatment allocation remaining concealed from the investigators conducting the surgery or experiments. There was no noticeable difference in the general 
behavior, appearance, or mortality rate between the animals treated with hIgG, control buffer, or MPSS. Experimental schematic of acute studies is shown in Fig. 1.

\section{Biochemical analyses}

Biochemical analyses were performed on 52 rats following SCI (hIgG $0.02 \mathrm{~g} / \mathrm{kg}(n=9), \operatorname{hIgG} 0.2 \mathrm{~g} / \mathrm{kg}(n=6)$, hIgG $0.4 \mathrm{~g} / \mathrm{kg}(n=6)$, hIgG $1 \mathrm{~g} / \mathrm{kg}(n=6), \mathrm{hIgG} 2 \mathrm{~g} / \mathrm{kg}$ $(n=6)$, control buffer $(n=6)$, MPSS $(0.03 \mathrm{~g} / \mathrm{kg})(n=7)$, and sham $(n=6))$. Rats were sacrificed at $24 \mathrm{~h}$ for various assays (western blot, proteome profiler, and myeloperoxidase (MPO) assay). Each animal was deeply anesthetized with isofluorane and transcardially perfused with $180 \mathrm{ml}$ of ice-cold $1 \times$ phosphate-buffered saline (PBS). The spleens were subsequently removed and weighed. A $2-\mathrm{cm}$ length of the spinal cord, centered at the injury epicenter, was dissected. The meninges were removed, and the cord was immediately frozen with dry ice. For tissue processing, the spinal cords were thawed and homogenized with $1 \times$ PBS without calcium and magnesium (Wisent) containing 1:1000 protease and phosphatase inhibitors $(100 \times)$ (Thermo Scientific). The homogenate was split for the respective assays and frozen in liquid nitrogen.

\section{Myeloperoxidase activity assay}

MPO activity was determined using a MPO fluorometric kit available from Assay Designs (Enzo Life Sciences), according to the manufacturer's instructions. To prepare the homogenate, the cellular membranes were disrupted and the blood was removed by homogenizing the spinal cord tissue in the provided homogenization buffer (without detergent) containing $10 \mathrm{mM} \mathrm{N}$-ethylmaleimide. The samples were then centrifuged at $4{ }^{\circ} \mathrm{C}$ at $12,000 \mathrm{~g}$ for 20 mins, and the supernatant was removed. MPO was released from the granules in pelleted material by sonicating in solubilization buffer containing $0.5 \%$ of the detergent hexadecyltrimethylammonium $(w / v)$ and also by exposing the mixture to two freeze/thaw cycles. The samples were then centrifuged at $8000 \mathrm{~g}$ for $20 \mathrm{mins}$ at $4{ }^{\circ} \mathrm{C}$. A Perkin-Elmer plate reader measured the fluorescence intensity of the resultant supernatants, with excitation wavelength at $530 \mathrm{~nm}$ and emission wavelength at $590 \mathrm{~nm}$. A calibration curve run concurrently with the samples was used to determine the MPO activity from the measured relative fluorescence intensity.

\section{Western blot}

Homogenate was solubilized in $200 \mu \mathrm{l}$ of RIPA buffer (25 mM Tris- $\mathrm{HCl}$ pH 7.6, $150 \mathrm{mM} \mathrm{NaCl}, 1 \% \mathrm{NP}-40,1 \%$ sodium deoxycholate, $0.1 \%$ sodium dodecyl sulfate; Thermo Fisher Scientific) containing a 100× cocktail of phosphatase and protease inhibitors and EDTA (Thermo Scientific). Samples were spun down at $14,140 \mathrm{~g}$ at $4{ }^{\circ} \mathrm{C}$ for 20 mins. The protein concentration of each sample was measured using the bicinchoninic acid assay (Thermo Scientific). To run the western blot, all samples had $20 \mu \mathrm{g}$ of total protein and were separated using sodium dodecyl sulfate polyacrylamide gel electrophoresis with $4 \%$ stacking- $12 \%$ resolving gel. Following electrophoresis, the gel was transferred onto a nitrocellulose membrane for $1 \mathrm{~h}$ at $100 \mathrm{~V}$. The membrane was then washed in $0.2 \%$ Tween Tris-buffered saline (TBS-T) and blocked for $1 \mathrm{~h}$ in TBS-T $+5 \%$ milk $(w / v)$. The primary antibodies used (concentration, incubation time, purpose) are listed in Table 1. The secondary antibody incubation step was accomplished at room temperature for $1 \mathrm{~h}$ with 1:3000 goat anti-rabbit HRP (Biorad). The membrane was washed with TBS-T three times (10 mins each time) between each antibody incubation step. Enhanced chemiluminescence (ECL; Perkin Elmer) substrate for horseradish peroxidase (HRP) was used to detect the signal. Densitometry analysis was accomplished using ImageJ software.

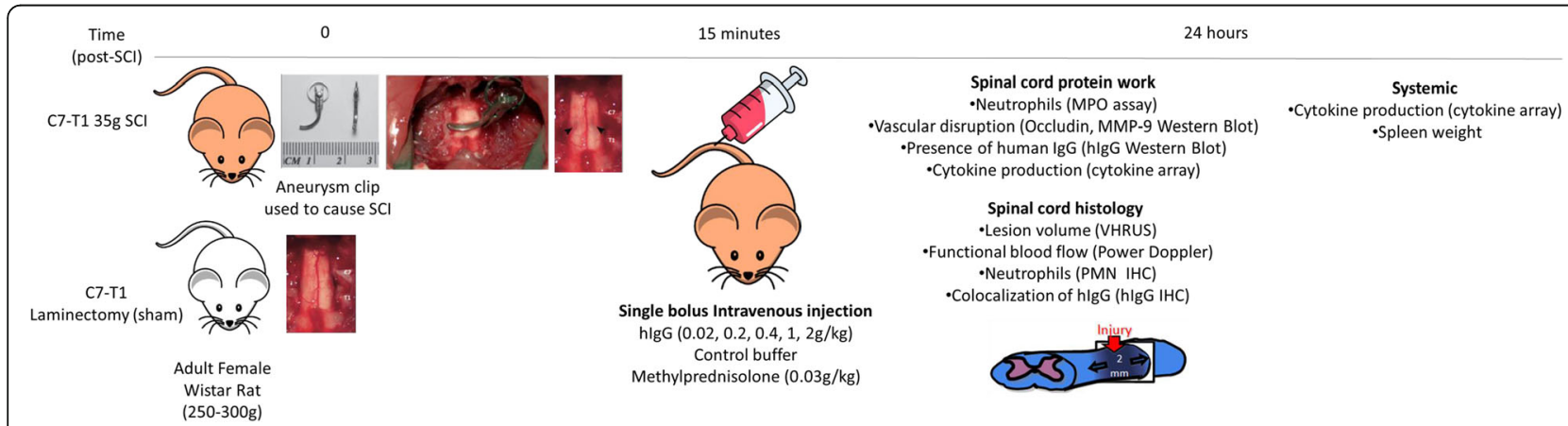

Fig. 1 Illustration depicting the experiments and protocol applied. Adult female Wistar rats (250 to $300 \mathrm{~g}$ ) received either a C7-T1 35g clipcompression injury or sham surgery (C7-T1 laminectomy). At 15 mins post-injury, a single bolus of hlgG $(0.02,0.2,0.4,1$, or $2 \mathrm{~g} / \mathrm{kg}$ ), control buffer, and MPSS (immunosuppressant; $0.03 \mathrm{~g} / \mathrm{kg}$ ) were administered to the injured rats through the tail vein. At 24 hours (h) post-SCl, the spinal cord was collected from the rats for various assays to analyze the local acute inflammatory response. Another group of rats was used for VHRUS, Power Doppler, and immunohistochemistry $(\mathrm{HC})$ analyses. For protein and histology work, $2 \mathrm{~cm}$ of the spinal cord centered at the epicenter was obtained 
Table 1 List of primary antibodies used for western blot, concentration, incubation parameters, and purpose

\begin{tabular}{llll}
\hline Antibody & Concentration & Incubation time and conditions & Application \\
\hline Rabbit anti-rat Iba-1; Wako Laboratory; Chemicals 019-19741 & $1: 1000$ & Overnight; $4{ }^{\circ} \mathrm{C}$ & Resident microglia activation \\
Rabbit anti-rat MMP-9; Millipore; AB19016 & $1: 3000$ & Overnight; $4{ }^{\circ} \mathrm{C}$ & Blood-spinal cord barrier degradation \\
Rabbit anti-hlgG; Abcam; AB109849 & $1: 5000$ & Overnight; $4{ }^{\circ} \mathrm{C}$ & Human IgG in the spinal cord \\
Goat anti-rat occludin; sc-8144 & $1: 500$ & Overnight; $4{ }^{\circ} \mathrm{C}$ & Blood spinal-cord barrier integrity \\
Mouse anti-rat ZO-1; MABT11 & $1: 250$ & Overnight; $4{ }^{\circ} \mathrm{C}$ & Blood spinal-cord barrier integrity \\
Rabbit anti-rat VCAM-1; Abcam; AB134047 & $1: 4000$ & Overnight; $4{ }^{\circ} \mathrm{C}$ & Vascular adhesion molecule \\
Mouse anti-rat B-actin HRP conjugated; ab49900 & $1: 10000$ & $1.5 \mathrm{~h}$; room temperature & Loading control \\
\hline
\end{tabular}

\section{Proteome profiler}

Nine rats were used for the proteome profiler (control buffer $n=3$, sham $n=3$, hIgG $2 \mathrm{~g} / \mathrm{kg} n=3$ ). The expression of rat cytokines in the spinal cord (after different treatment administrations) was detected using a commercially available proteome profiler rat cytokine array kit (Panel A) (R\&D systems) according to the manufacturer's instructions and with $100 \mu \mathrm{g}$ protein per sample.

\section{Histological, functional blood flow, and immunohistochemical analysis}

For histology and functional blood flow analyses, 24 rats (control buffer $n=6$, hIgG $0.4 \mathrm{~g} / \mathrm{kg} n=6$, hIgG $2 \mathrm{~g} / \mathrm{kg}$ $n=6$, sham $n=6$ ) were analyzed with in vivo very highresolution ultrasound (VHRUS) and Power Doppler imaging, as previously described [19]. At 24 h after injury, the animals were anesthetized using isofluorane and placed on an imaging platform (Vevo Imaging Station, VisualSonics, Toronto, Ontario, Canada, http:// www.visualsonics.com) with a custom-made stabilization frame. The injury was exposed with a midline incision and retraction of the paraspinal muscle layers. Ultrasound gel (scanning gel, Medi-Inn, www.medi-inn.com) was placed on the dura mater and scanned with the VHRUS probe (44 MHz, Vevo 770, VisualSonics) in three-dimensional (3D) B-mode. The 3D B-mode scans were analyzed using Image J software as previously described [19], with minor modifications. Briefly, the bright pixels were delineated by one independent blinded observer within 19 central sagittal image slices, and these slices were used to generate a reproducible lesion volume with the TrakEM2 plugin. For Power Doppler imaging, functional blood flow was quantified by measuring the percent area of power Doppler signal (color threshold positive pixels) in a standardized spinal cord region within the image slices. The scan speed was 2.0 $\mathrm{mm} / \mathrm{s}$, and the wall filter was $2.5 \mathrm{~mm} / \mathrm{s}$.

Subsequently, the animals were deeply anesthetized with isofluorane and perfused with $60 \mathrm{ml}$ of ice-cold $1 \times$ PBS and $180 \mathrm{ml}$ of paraformaldehyde (Sigma Aldrich) $(4 \% w / v$ in $1 \times$ PBS, $\mathrm{pH} 7.4)$. Two centimeters of the spinal cord (centered at the injury epicenter) was dissected and post-fixed for $5 \mathrm{~h}$ with $10 \%$ sucrose (Bioshop) and 4\% PFA-PBS solution. The spinal cord was subsequently cryoprotected in $30 \%$ sucrose PBS solution. The spinal cord tissue $(2 \mathrm{~cm}$ centered at the injury epicenter) was embedded in M1 media (Thermo Fisher Scientific) and stored at $-80^{\circ} \mathrm{C}$. The spinal cords were cryosectioned at $20 \mu \mathrm{m}$ thickness.

The frozen tissue sections were stained with various antibodies diluted with blocking solution made of $1 \times$ PBS containing 5\% $w / v$ milk (Bioshop), 1\% $w / v$ bovine serum albumin (Sigma Aldrich), and 0.03\% Triton X-100 (Thermo Scientific). Antibody, concentration, and purpose are listed in Table 2. The tissue sections were blocked for $1 \mathrm{~h}$ in room temperature with a blocking solution. Secondary antibody alone (no primary antibody) served as the negative control. Washing steps after antibody application were accomplished with $1 \times$ PBS washes three times each for $10 \mathrm{~min}$, with the last wash also containing 1:1000 DAPI (4',6-diamidino-2-phenylindole) to counterstain for the nuclei. The slides were mounted onto the coverslips using Mowiol (Sigma Aldrich).

\section{Stereological quantification of neutrophil infiltration and cellular localization/tissue distribution of IgG at 24 h post- $\mathrm{SCl}$}

For stereological quantification, tissue was systematically sampled at every $240 \mu \mathrm{m}$ over a distance of $4800 \mu \mathrm{m}$, which was centered at the lesion epicenter of each animal. Neutrophils were quantified stereologically using the Zeiss Axioplan Deconvolution Microscope (with AxioVision), with neutrophils being $\mathrm{PMN}^{+} / \mathrm{DAPI}^{+}$. For co-localization of hIgG with rat spinal cord blood vessels, microglia, neutrophils, astrocytes, pericytes, and VCAM-1, tissue was imaged at the lesion epicenter using confocal microscopy (Nikon Eclipse Ti) at $\times 120$.

\section{Tissue preservation analysis}

At 6 weeks post-SCI, the spinal cords were perfused in an identical fashion as described for histological, functional blood flow, and immunohistochemical analyses. The tissue sections from 22 animals (control buffer $n=6$, hIgG $(0.4 \mathrm{~g} / \mathrm{kg}) n=6$, hIgG $(2 \mathrm{~g} / \mathrm{kg}) n=6$, sham 
Table 2 List of primary antibodies used for immunohistochemistry, concentration, incubation parameters, and purpose

\begin{tabular}{|c|c|c|c|}
\hline Antibody & Concentration & Incubation time and conditions & Application \\
\hline $\begin{array}{l}\text { Rabbit anti-rat polymorphonuclear cells (PMN) conjugated } \\
\text { with FITC (Cedarlane; CLFAD51140) }\end{array}$ & 1:100 & Overnight; $4^{\circ} \mathrm{C}$ & Neutrophil infiltration \\
\hline Rabbit anti-rat Iba-1 (Wako Laboratory Chemicals; 019-19741) & $1: 300$ & Overnight; $4^{\circ} \mathrm{C}$ & Resident microglia \\
\hline Lycopersicon esculentum (tomato) (FITC conjugated; Sigma; L0401) & 1:500 & Overnight; $4^{\circ} \mathrm{C}$ & Blood vessel \\
\hline Rabbit anti-GFAP (Millipore; AB5804) & 1:500 & Overnight; $4^{\circ} \mathrm{C}$ & Astrocytes \\
\hline $\begin{array}{l}\text { Mouse anti-NG2 chondroitin sulfate proteoglycan antibody } \\
\text { (Millipore; AB5384) }\end{array}$ & $1: 250$ & Overnight; $4^{\circ} \mathrm{C}$ & Pericytes \\
\hline Rabbit PDGF receptor beta antibody [Y92] (Abcam; ab32570) & $1: 250$ & Overnight; $4^{\circ} \mathrm{C}$ & Pericytes \\
\hline Rabbit anti-rat VCAM-1; Abcam; AB134047 & $1: 250$ & Overnight; $4^{\circ} \mathrm{C}$ & Vascular adhesion molecul \\
\hline $\begin{array}{l}\text { Goat anti-human IgG }(\mathrm{H}+\mathrm{L}) \text { (cross-adsorbed secondary antibody } \\
\text { AlexFluor 568) (Fisher-Invitrogen) }\end{array}$ & $1: 150$ & $2 \mathrm{~h}$; room temperature & Human lgG \\
\hline
\end{tabular}

$n=4)$ were systematically sampled at every $240 \mu \mathrm{m}$ over a distance of $3600 \mu \mathrm{m}(1800 \mu \mathrm{m}$ rostral and caudal of the epicenter). The tissue sections were stained with luxol fast blue (LFB) overnight at $56^{\circ} \mathrm{C}$. Hematoxylin and eosin (H\&E) was used to stain for the cell nuclei and counterstain, respectively. Unbiased measurements were made with a Cavalieri probe (Stereoinvestigator, MBF Bioscience, Williston, VT) for total tissue, gray matter, white matter, lesion, and cavity volumes.

\section{Neurobehavioral assessment of functional recovery}

All neurobehavioral assessments were performed and analyzed by examiners blinded to the treatment groups. A total of 42 animals (control buffer $n=12$, hIgG $(0.4 \mathrm{~g} / \mathrm{kg}$ ) $n=12$, hIgG $(2 \mathrm{~g} / \mathrm{kg}) n=12$, sham $n=6)$ were used for neurobehavioral assessments, which were performed once per week for 6 weeks post-SCI. This neurobehavioral assessment paradigm has been previously used in our laboratory $[15,20]$. Hindlimb function was tested using the 21-point open-field Basso-Beattie-Bresnahan (BBB) Locomotor Scale. To assess the whole-body and trunk motor function, the inclined plane test was performed. The animals were placed on a flat plane surface, and each subsequent trial increased the angle of the plane at increments of $5^{\circ}$. The rats were placed with their body axis parallel to the plane. The rats were required to maintain their body position on the plane for $5 \mathrm{~s}$ for 3 of 5 attempts. Forelimb strength was tested using a grip strength meter. For this strength test, the animals were held by the hindlimbs and lower abdomen and drawn backwards at a consistent speed within reach of a metal rung connected to the strength apparatus. The animals grasp the rung reflexively, and a strength meter measures the maximal force achieved when the grip was broken. Strength was averaged over 5 successful grasps. To test for neuropathic pain, the animals were subjected to the tail flick test. Using a specialized device, the rats were wrapped in a blanket while the tail was left exposed to a beam of light, which served as a heat source. The time elapsed before the rat flicked its tail in response to heat was recorded.

\section{Statistical analysis}

Data are reported as mean \pm standard error of the mean (SEM). For biochemical, immunohistochemical, molecular, and ultrasound analyses, comparisons were based on a one-way ANOVA (analysis of variance) and Tukey's post-hoc test, with multiple $t$ tests (Holm-Sidak method) performed for proteome profiler. Pearson's correlation coefficient was used to determine ZO-1, occludin, and MMP-9 relations. For neurobehavioral recovery and tissue preservation, two-way ANOVA and Tukey's posthoc tests were performed. All statistical analyses were performed using Prism 6.0 Software (GraphPad Version 6.01). Differences were considered significant if $p<0.05$.

\section{Results}

\section{Cellular localization and tissue distribution of hlgG in the spinal cord $24 \mathrm{~h}$ post-SCl}

To determine if the presence of hIgG in the spinal cord is necessary for dose-dependent immunomodulatory effects after SCI, a western blot for hIgG was completed. Previous work has shown $[13,15]$ that intravenously administered hIgG enters the injured cord through the compromised BSCB. Yet, it is unclear if the penetration of hIgG into the injured spinal cord is a prerequisite for hIgG's observed effects. As demonstrated in the hIgG western blot, there was a dosage-dependent increase in hIgG that reached the injured spinal cord at $24 \mathrm{~h}$ postSCI (Fig. 2a), while there was no cross-reactivity with rat immunoglobulin G (Fig. 2b).

To complement the hIgG western blot, IHC was performed to detect hIgG levels at $24 \mathrm{~h}$ post-SCI as well as potential co-localization with other cell types in the rat spinal cord. Epifluorescent images were acquired using a $\times 20$ objective at the lesion epicenter. At $24 \mathrm{~h}$ after injection, the presence of hIgG increased in a dosedependent manner in rats treated with hIgG and was 


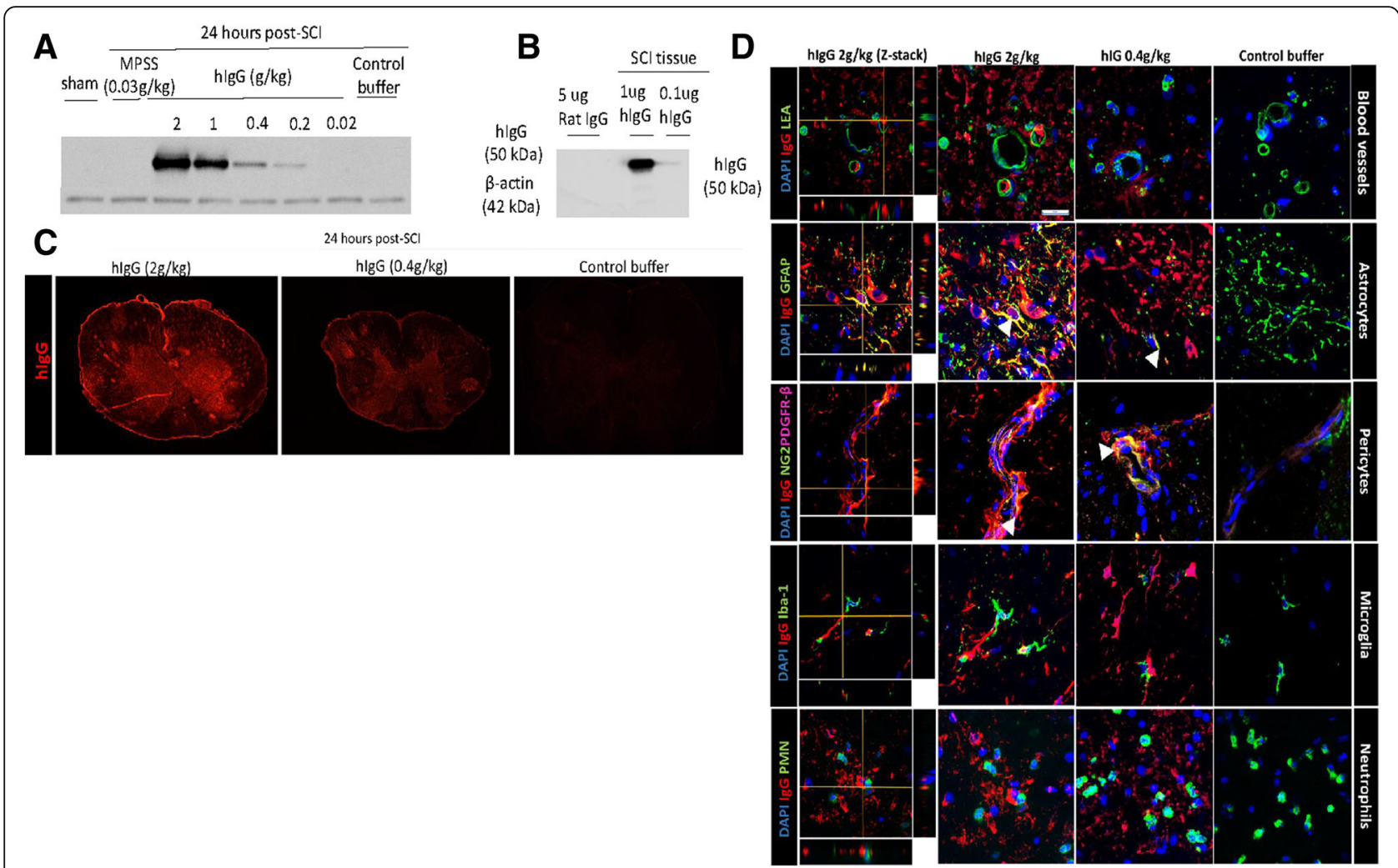

Fig. 2 hlgG crosses the BSCB at $24 \mathrm{~h}$ post-SCl. The presence of hlgG in the spinal cord was determined in order to evaluate if it is associated with the immunomodulatory effects of hlg G after $\mathrm{SCl}$. a Western blot was performed to determine the levels of hlgG in the spinal cord after different treatments. b Relative to control buffer and hlgG $(0.4 \mathrm{~g} / \mathrm{kg})$, high-dose hlgG (1 and $2 \mathrm{~g} / \mathrm{kg}$ ) administered at $15 \mathrm{~min}$ post-SCl increased the hlgG levels in the injured spinal cord at $24 \mathrm{~h}$ post-SCl. c Western blot results are complemented with immunohistochemistry, as in the representative fluorescence images there is a stronger staining of hlgG in the spinal cords treated with hlgG $(2 \mathrm{~g} / \mathrm{kg})$ as compared to hlgG $(0.4 \mathrm{~g} / \mathrm{kg})$ and control buffer. $\mathbf{d}$ The blood vessels (LEA), neutrophils (PMN), microglia (Iba-1), and astrocytes (GFAP) are stained green, pericytes (NG2 green, PDGFR- $\beta$ : fuchsia), and hlgG are stained red. Confocal images $(\times 120)$ demonstrate that hlgG crosses the compromised BSCB in injured animals. Representative images demonstrate hlgG in the vicinity of resident microglia and neutrophils, but hlgG colocalizes with the hlgG, astrocytes, pericytes, and blood vessels. For both $\mathbf{c}$ and $\mathbf{d}$, a hlgG-positive signal was not observed in the spinal cord of rats injected with control buffer. $\mathbf{d}$ Scale bars represent $10 \mu \mathrm{m}$ in length

absent in rats treated with the control buffer (Fig. 2c). hIgG was found inside and outside the spinal cord vasculature (marked by FITC LEA positive staining) in the spinal cord of injured animals; re-affirming that a compromised BSCB after SCI enables hIgG to enter into the injured spinal cord (Fig. 2d). Further, as demonstrated with representative confocal images $(\times 120)$, hIgG surrounded the resident microglia, neutrophils, and blood vessels, as indicated by FITC-positive PMN, Iba-1, and LEA staining. Importantly, hIgG co-localized with rat astrocytes, pericytes, and adhesion molecule, VCAM-1. Although our previous publication showed co-localization with rat astrocytes [15], we extended these findings to demonstrate potential interactions between hIgG and the spinal cord neurovascular unit (astrocytes and pericytes) as well as immune cell adhesion molecules [21]. Further, while Iba-1 stains for monocytes and microglia, Iba-1-positive cells were likely microglia, as monocytes infiltrate the injured spinal cord at 3 days post-SCI [22].

\section{hlgG decreases damage to the spinal cord vasculature} after $\mathrm{SCl}$

Interactions between hIgG and the spinal cord neurovascular unit prompted us to evaluate the potential effects on the BSCB. In SCI, physical trauma decreases the expression of tight junction proteins, which are needed to maintain BSCB integrity [23]. In addition, the integrity of the BSCB can be further compromised by upregulation of inflammatory enzymes that degrade the components [24]. Abnormalities in the permeability and function of the BSCB after SCI are directly linked with infiltration of immune cells, which exacerbate damage from the primary injury. A key inflammatory enzyme is matrix metalloproteinase-9 (MMP-9), which is a zincand calcium-dependent endopeptidase produced by neutrophils and microglia after SCI to degrade the major components of the basal lamina and tight junctions. MMP-9 facilitates the entrance of immune cells and initiates SCI-induced secondary damage [24, 25]. We have previously shown that hIgG $(0.4 \mathrm{~g} / \mathrm{kg})$ reduces MMP-9 
expression at $24 \mathrm{~h}$ post-SCI [15]. Western blots were performed to evaluate dose-dependent effects of hIgG on the expression of MMP-9 at $24 \mathrm{~h}$ post-SCI and consequential effects on BSCB integrity (spinal cord protein expression of $\mathrm{ZO}-1$ and occludin).

The western blots demonstrated that the presence of inflammatory conditions can cleave pro-MMP-9 (101 kDa) to become active MMP-9 (92 kDa) [25] (Fig. 3a). The literature indicates that peak expression of active MMP-9 at $24 \mathrm{~h}$ post-SCI coincides with maximum neutrophil infiltration [22, 26]. At $24 \mathrm{~h}$ post-SCI, there was a dosedependent decrease in active MMP-9 expression, with a significant difference between $\mathrm{hIgG}(2 \mathrm{~g} / \mathrm{kg})$ and the control buffer (one-way ANOVA, $p<0.0001$; Tukey's posthoc test, $p=0.0056$ ) as well as between the control buffer and hIgG $(0.4 \mathrm{~g} / \mathrm{kg})$ (one-way ANOVA, $p<0.0001$; Tukey's post-hoc test, $p=0.0241$ ) (Fig. 3c). The greater expression of active MMP-9 corresponds to the degradation of tight junctions that disrupt the BSCB, which is shown by the decrease in the expression of tight junction proteins (occludin and ZO-1) (Fig. 3b). Dose-dependent increases in both occludin and zonula occludens-1 (ZO-1) were observed in western blot for both hIgG-treated $(0.4 \mathrm{~g} / \mathrm{kg})$ and hIgG-treated $(2 \mathrm{~g} / \mathrm{kg})$ samples relative to the control buffer (Fig. 3b). Quantification of occludin and ZO-1 protein expressions is found in Figs. $3 \mathrm{~d}$ and e (occludin: oneway ANOVA, $p<0.0001$; Tukey's post-hoc test, $p=0.0317$ and $p<0.0001$ respectively for hIgG $(0.4 \mathrm{~g} / \mathrm{kg})$ and hIgG $(2 \mathrm{~g} / \mathrm{kg})$; ZO-1: one-way ANOVA, $p<0.0001$; Tukey's post-hoc test, $p=0.0301$ and $p<0.0001$ respectively for hIgG $(0.4 \mathrm{~g} / \mathrm{kg})$ and hIgG $(2 \mathrm{~g} / \mathrm{kg}))$. Reduced MMP-9 activity is associated with a protective effect on $\mathrm{ZO}-1$ and occludin, as there are significant negative correlations in the expression of active MMP-9/ZO-1 and active MMP9/occludin (Figs. 3f, g). Loss and degradation of tight junction proteins have been implicated in the hyperpermeability seen in the BSCB after SCI.

This greater preservation of BSCB integrity prompted us to evaluate the effect of hIgG treatment on functional vascularity, which is a measure of active blood flow. Power Doppler imaging was performed to evaluate the functional blood flow at $24 \mathrm{~h}$ post-SCI (Fig. 3h, i). Relative to the control buffer, functional blood flow after SCI was improved with hIgG $(2 \mathrm{~g} / \mathrm{kg}$ ) (one-way ANOVA, $p<0.0001$; Tukey's post-hoc test). In addition, functional blood flow was significantly improved between hIgG $(0.4 \mathrm{~g} / \mathrm{kg})$ and hIgG $(2 \mathrm{~g} / \mathrm{kg})$ (one-way ANOVA, $p<$ 0.0001; Tukey's post-hoc test, $p<0.0001$ ). Representative images of functional blood flow are seen in Fig. $3 \mathrm{~h}$.

\section{hlgG significantly reduces neutrophil infiltration at $24 \mathrm{~h}$ post-SCI}

The preservation of the spinal cord neurovasculature encouraged us to evaluate the changes in immune cell infiltration, as one physiological function of the BSCB is to limit the entrance of immune cells into the spinal cord [24]. Neutrophils are the first systemic immune cell to infiltrate after SCI, with the number of cells increasing between 3 and $6 \mathrm{~h}$ after injury, and peak infiltration observed at $24 \mathrm{~h}$ post-SCI $[2,22]$. The literature has largely suggested that reducing neutrophil infiltration improves recovery in both rat and mouse SCI models [4, $5,12,15]$, although it has also been reported that neutrophil depletion worsens the neurological recovery after SCI [27]. Specifically, our laboratory and others have demonstrated that hIgG administration attenuates neutrophil infiltration into the cord after SCI $[12,15]$. MPO is an enzyme found primarily in the azurophilic granules of neutrophils, and its activity is an excellent correlate to the absolute number of neutrophils in the cord. Thus, MPO is a specific and sensitive marker to quantify neutrophil infiltration into injured tissue $[4,15]$. At $24 \mathrm{~h}$ post-SCI, MPO activity was found to be significantly higher in animals with SCI compared to sham animals. Our laboratory previously showed that hIgG $(0.4 \mathrm{~g} / \mathrm{kg})$ significantly reduced MPO activity $24 \mathrm{~h}$ after SCI [15], and the present study reproduced this finding. Specifically, hIgG $(0.4 \mathrm{~g} / \mathrm{kg})$ significantly reduced MPO activity as compared to the control buffer (one-way ANOVA, $p<0.0001$; Tukey's post-hoc test, $p=0.0019$ ). Further, we showed that hIgG $(2 \mathrm{~g} / \mathrm{kg})$ had superior immunomodulatory effects relative to both the control buffer and hIgG $(0.4 \mathrm{~g} / \mathrm{kg})$ (one-way ANOVA, $p<0.0001$; Tukey's posthoc test, $p<0.0001$ and $p=0.0178$, respectively). To complement the MPO assay, immunohistochemistry was performed to detect neutrophil infiltration at $24 \mathrm{~h}$ post$\mathrm{SCI}$, and unbiased stereology was used to quantify the infiltration in response to different hIgG doses (Fig. 4b). Importantly, in the injured rats treated with hIgG $(2 \mathrm{~g} / \mathrm{kg})$, there were significantly fewer neutrophils found in the spinal cord relative to rats treated with hIgG $(0.4 \mathrm{~g} / \mathrm{kg})$ and control buffer (one-way ANOVA, $p<0.0001$; Tukey's post-hoc test, $p=0.0022$ and $<0.0001$ ). Furthermore, relative to the control buffer, hIgG $(0.4 \mathrm{~g} / \mathrm{kg})$ reduced neutrophil infiltration (one-way ANOVA, $p<0.0001$; Tukey's post-hoc test, $p=0.0072$ ) (Fig. 4c). This is aligned with our previously published results [15].

\section{hlgG changes the expression of both inflammatory and anti-inflammatory cytokines in the spinal cord at $24 \mathrm{~h}$ post-SCI}

To explain how hIgG $(2 \mathrm{~g} / \mathrm{kg})$ can impose immunomodulatory effects on neutrophils, we sought to identify if these changes are associated with altered cytokine production in the injured spinal cord. A proinflammatory or anti-inflammatory microenvironment in the spinal cord can influence the recruitment, activation, and effector functions of immune cells. Using 


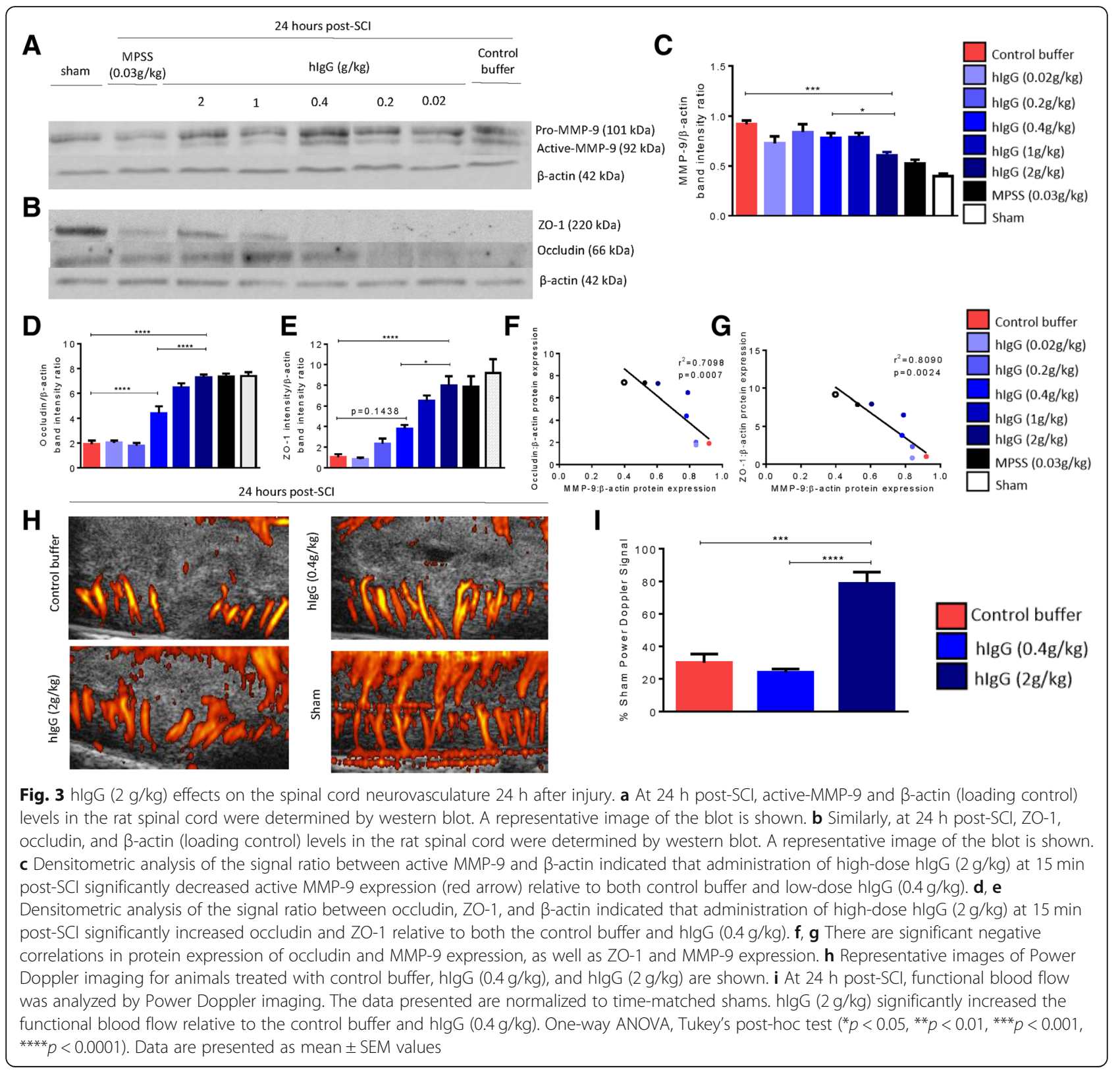

the $R \& D$ proteome profiler array (Fig. 5a), relative to control buffer, hIgG $(2 \mathrm{~g} / \mathrm{kg})$ treatment altered the levels of both anti-inflammatory cytokines (interleukin (IL)-10, fractalkine $\left(\mathrm{CX}_{3} \mathrm{CL} 1\right)$, IL-13) and inflammatory cytokines (IL-1 $\beta$, TNF- $\alpha$, CINC- $2 \alpha / \beta$, CINC-3) (multiple $t$ tests; Holm-Sidak correction; IL-10, $p=$ 0.0006; $\mathrm{CX}_{3} \mathrm{CL} 1, p=0.001$; IL-1 $\beta, p=0.002$; IL-1 $\beta, p=$ $0.004 ; \quad$ TNF- $\alpha, \quad p=0.0023 ; \quad$ CINC- $2 \alpha / \beta, \quad p=0.0032$; CINC-3, $p=0.0029$; IL-13, $p=0.07$ ) (Fig. 5c). Representative images of the array membrane for respective cytokines are shown in Figs. 5a, b. The expression of the other cytokines detected by the R\&D proteome profiler is demonstrated with a heat map (Fig. 5d).
High-dose hlgG may interfere with immune cell trafficking by binding to vascular cell adhesion molecule-1

At $24 \mathrm{~h}$ post-SCI, relative to control buffer and hIgG $(0.4 \mathrm{~g} / \mathrm{kg})$, hIgG $(2 \mathrm{~g} / \mathrm{kg})$ significantly increased the splenic weight (Fig. 6a). Conversely, MPSS $(0.03 \mathrm{~g} / \mathrm{kg})$ significantly decreased the splenic weight. The spleen is a major source of immune cells after SCI, and gross structural changes in the spleen are adaptions to the immune response at acute time points [28]. As MPSS $(0.03 \mathrm{~g} / \mathrm{kg})$ and hIgG $(2 \mathrm{~g} / \mathrm{kg})$ had different effects on splenic weight, but both demonstrated anti-inflammatory effects at the injured spinal cord, this suggested potential changes in immune cell trafficking. Hence, protein expression of 


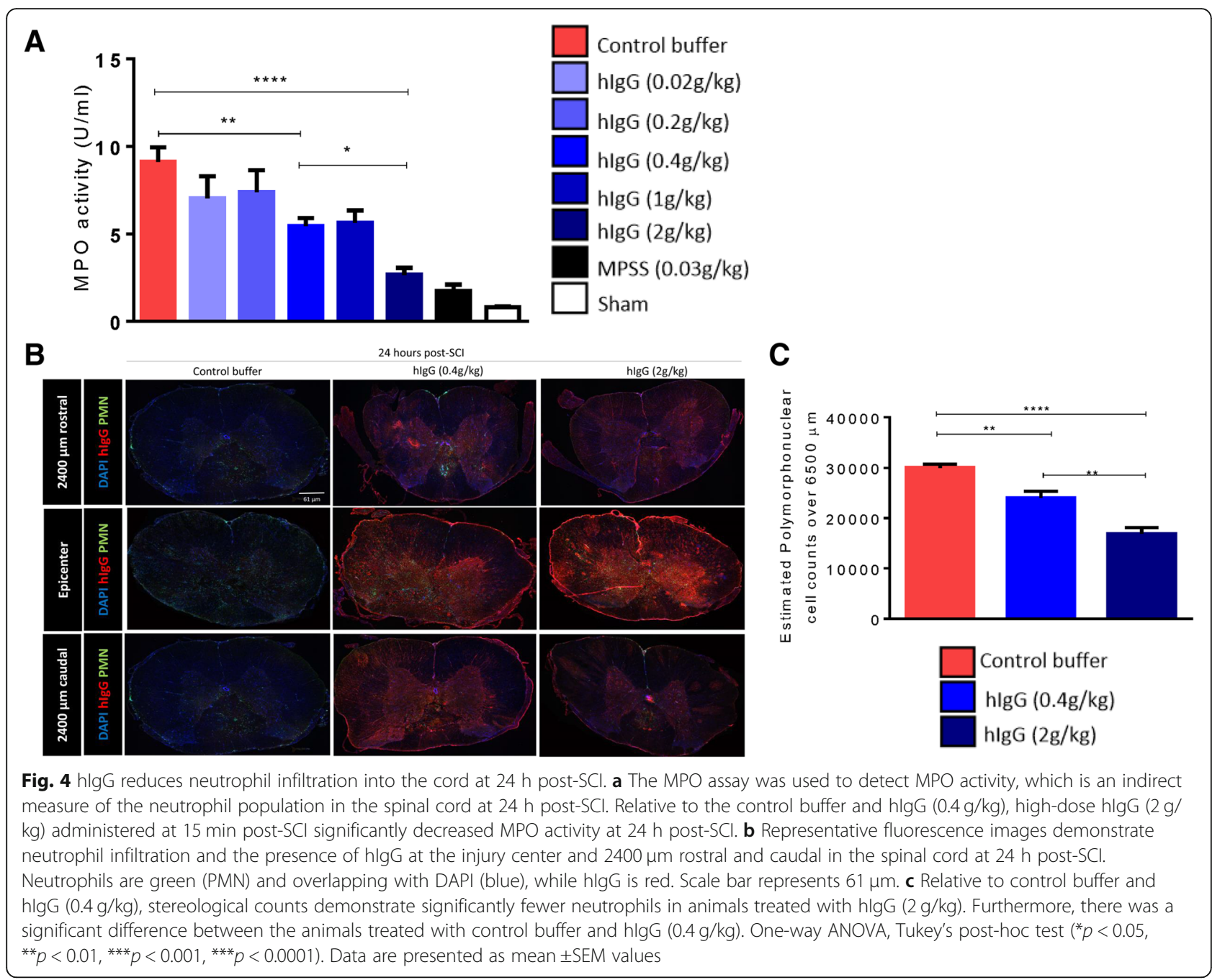

cytokines in serum after different treatments was evaluated. Using a commercially available rat cytokine array, we observed that hIgG $(2 \mathrm{~g} / \mathrm{kg})$ upregulated IL-8, MIP- $1 \alpha$, CCL-2/MCP-1, and IL-5, while MPSS $(0.03 \mathrm{~g} / \mathrm{kg})$ significantly downregulated the expression (Fig. 6b). Relative to the control buffer, vascular endothelial growth factor (VEGF) was also upregulated by hIgG treatment. However, of the hIgG-treated groups, expression was significantly lower in the hIgG $(2 \mathrm{~g} / \mathrm{kg})$ group.

Significant changes in the serum cytokine expression prompted the evaluation of relevant adhesion ligands, which are a major component of immune cell trafficking into injured tissue. Ligands used by neutrophils, such as vascular cell adhesion molecule-1 (VCAM-1) [29], are notable as neutrophils are the main population of infiltrating immune cells at $24 \mathrm{~h}$ post-SCI [22]. With immunohistochemistry, we observed that hIgG co-localized with spinal cord VCAM-1 (Fig. 6c). However, despite the previously observed anti-inflammatory effects of
hIgG, VCAM-1 protein expression in the spinal cord was not reduced by hIgG (2 g/kg) (Fig. 6d, e).

High-dose hlgG significantly reduces lesion tissue volume at $\mathbf{2 4} \mathrm{h}$ post-SCl, which translates to long-term neurobehavioral recovery and tissue preservation at 6 weeks post-SCI

While hIgG $(2 \mathrm{~g} / \mathrm{kg})$ had acute benefits by modulating the acute neuroinflammatory response at $24 \mathrm{~h}$ post-SCI, it was unknown if these molecular changes would translate into improved functional and tangible tissue preservation at both short-term ( $24 \mathrm{~h})$ and long-term (6 weeks) time points post-SCI. In order to analyze the effects of hIgG on neurobehavioral functional recovery, rats with SCI receiving either control buffer, hIgG $(0.4 \mathrm{~g} / \mathrm{kg})$, or hIgG $(2 \mathrm{~g} / \mathrm{kg})$ performed weekly behavioral assessments up to 6 weeks post-SCI (Fig. 7a). Functional recovery was tested using the inclined plane, BBB Locomotor Scale, grip strength, and tail flick. hIgG $(2 \mathrm{~g} / \mathrm{kg})$ animals 


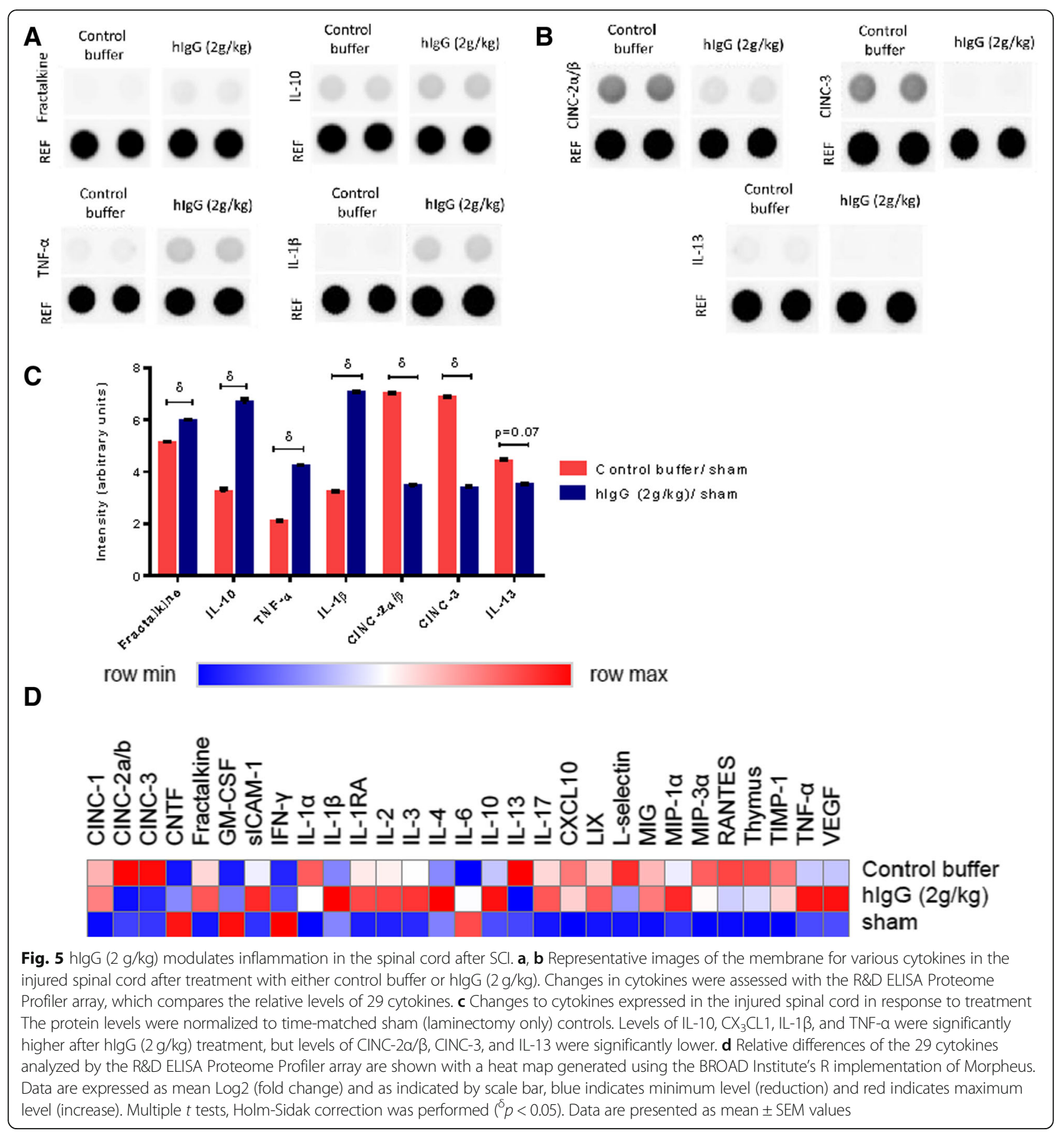

performed significantly better than those treated with control buffer and hIgG $(0.4 \mathrm{~g} / \mathrm{kg}$ ) (two-way ANOVA, $p<0.0001$ ) (Fig. 7b). Improvements were mostly observed at weeks 4,5 , and 6 for these behavioral assessments. For the inclined plane, hIgG $(2 \mathrm{~g} / \mathrm{kg})$ animals were observed to have improved whole-body and trunk motor function. The BBB indicated that hIgG $(2 \mathrm{~g} / \mathrm{kg})$ animals had a greater hindlimb motion, suggesting that hIgG-treated $(2 \mathrm{~g} / \mathrm{kg})$ animals had substantial weight support and extensive movement in all three joints, while control buffer and hIgG-treated $(0.4 \mathrm{~g} / \mathrm{kg})$ animals had no weight support and less extensive joint movement. hIgG-treated $(2 \mathrm{~g} / \mathrm{kg})$ animals also displayed greater forelimb grip strength. However, hIgG $(2 \mathrm{~g} / \mathrm{kg})$ had no effect on improving the neuropathic pain, as indicated by a lack of differences observed in the tail flick test. Sham animals did not display functional deficits.

In order to determine if acute immunomodulatory changes can lead to improved tissue preservation at acute and chronic time points, thus supporting neurobehavioral 


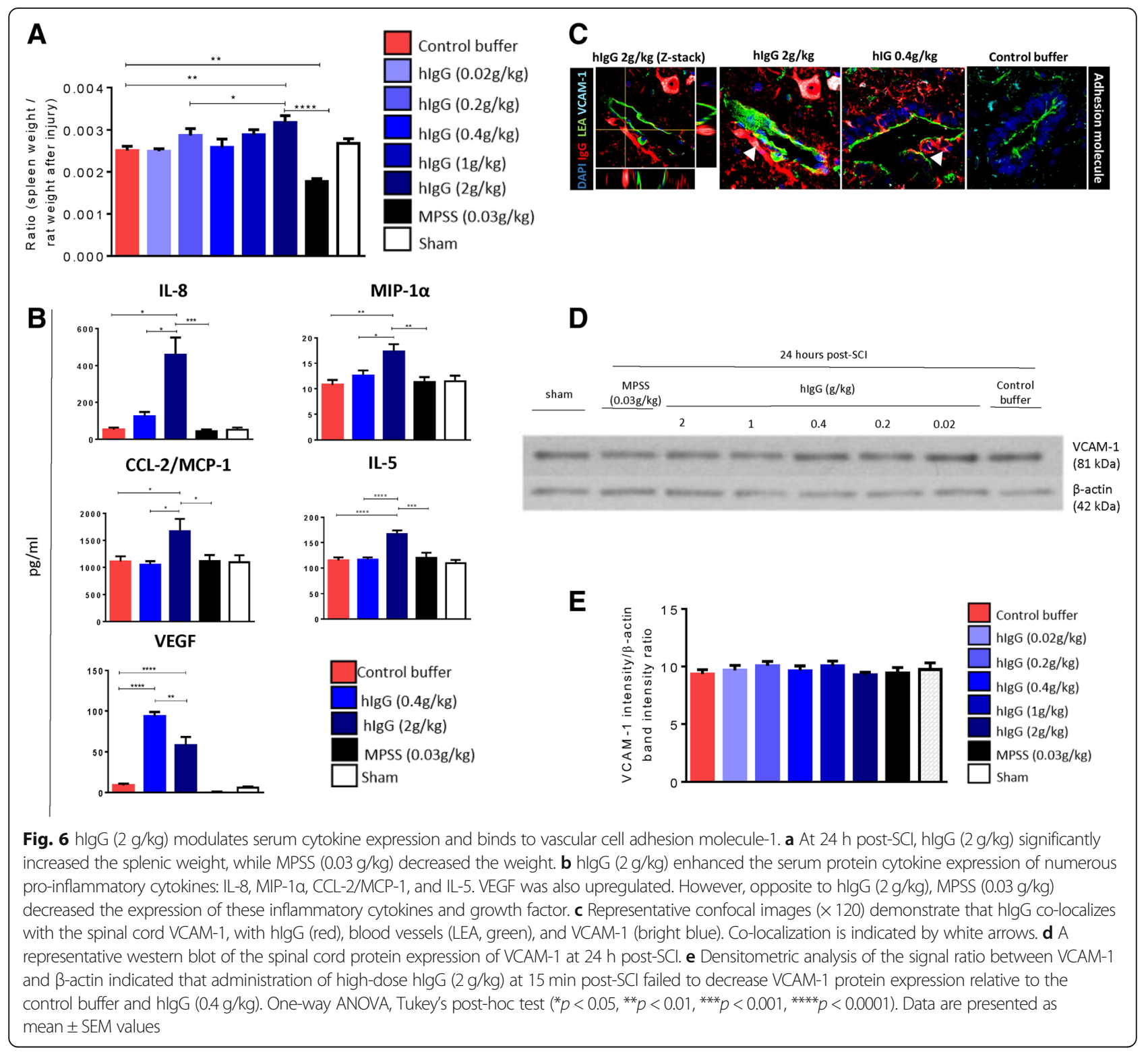

improvement, spinal cord histological analyses were performed at 1 day and 6 weeks post-SCI with in vivo VHRUS and LFB/HE staining, respectively. Using VHRUS, relative to both the control buffer and $\operatorname{hIgG}(0.4 \mathrm{~g} / \mathrm{kg})$, hIgG $(2 \mathrm{~g} / \mathrm{kg})$ treatment was able to reduce the lesion volume (one-way ANOVA, $p<0.001$; Tukey's post-hoc, $p<0.0001$ and $p<0.05$, respectively) (Fig. $8 \mathrm{a}, \mathrm{b}$ ). There was also a reduction in lesion volume between the control buffer and hIgG $(0.4 \mathrm{~g} / \mathrm{kg})$. A reduction in lesion volume can translate to increased tissue preservation. At 6 weeks post-SCI, LFB/HE quantification demonstrated hIgG (2 g/ $\mathrm{kg}$ ) was able to enhance tissue preservation by increasing the volumes of white and gray matters, as well as concurrently decreasing the lesion tissue and cavity volumes (Fig. 8c) (one-way ANOVA, $p<0.0001$ ). While protection conferred by hIgG ( $2 \mathrm{~g} / \mathrm{kg}$ ) occurs both rostral and caudal of the epicenter, the protection was most evident at the caudal regions of the injured spinal cord. The preservation of white matter and gray matter, along with a concurrent reduction of the lesion and cavity, is demonstrated by representative LFB/HE images in Fig. 8d. Of note, the acute differences observed with VHRUS between the control buffer and hIgG $(0.4 \mathrm{~g} / \mathrm{kg})$ were not detected with LFB/HE at 6 weeks post-SCI. Nevertheless, the preservation of tissue with hIgG is important, as it aligns with previous findings made by our laboratory and others $[12,13,15]$.

\section{Discussion}

In this study, a well-characterized model of SCI was used to carry out a dose-dependent examination of 


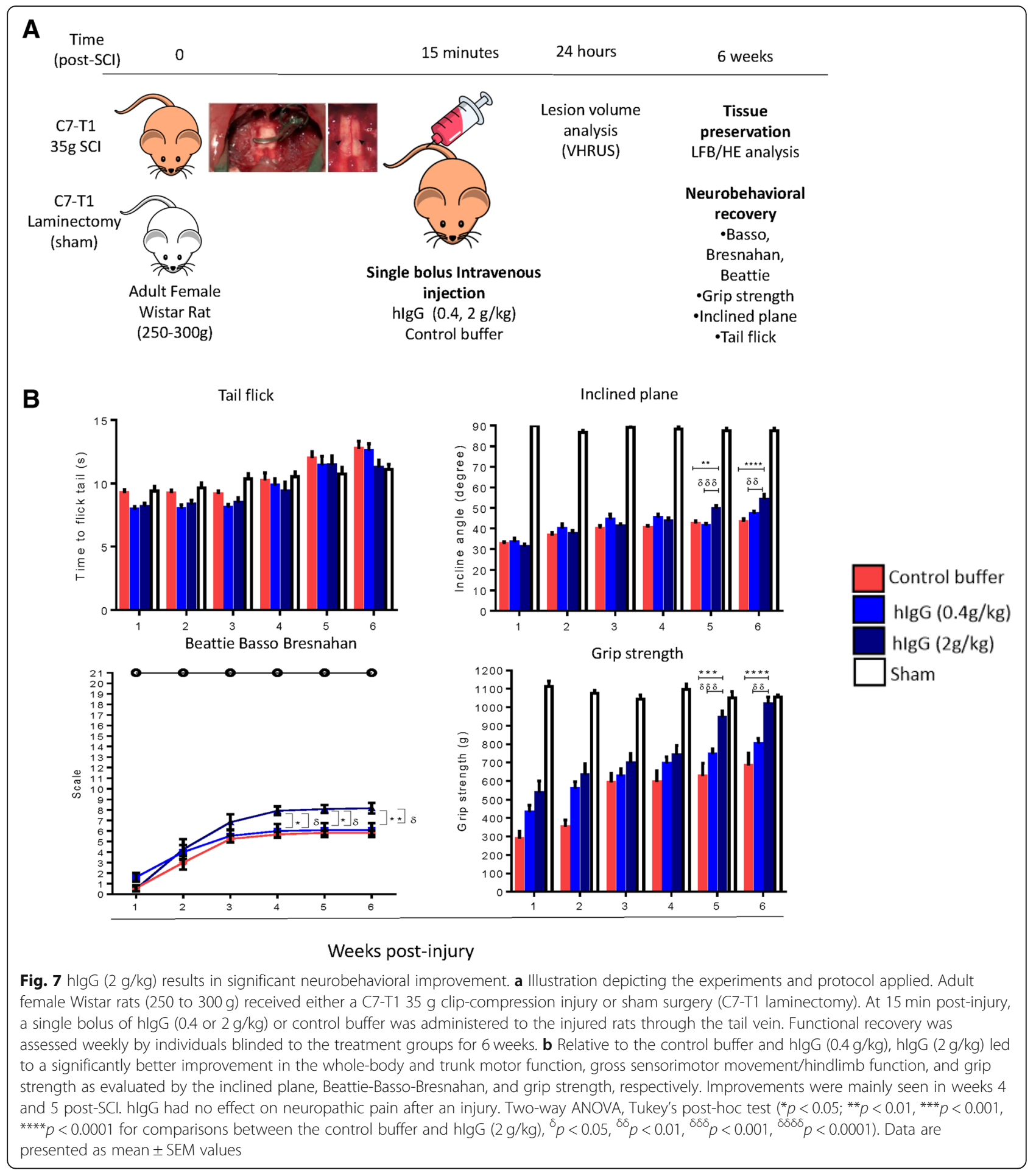

intravenously administered hIgG's potential to attenuate neuroinflammation after SCI in rats. Our current results demonstrate that hIgG $(2 \mathrm{~g} / \mathrm{kg})$ is more effective than hIgG $(0.4 \mathrm{~g} / \mathrm{kg})$ to treat $\mathrm{SCI}$ and provides evidence that the immunomodulatory effects of hIgG are mediated through preserving the spinal cord neurovascular unit. Specifically, high-dose hIgG $(2 \mathrm{~g} / \mathrm{kg})$ has significant protective effects on the spinal cord vasculature. These benefits are associated with reduced neutrophil infiltration, decreased expression of pro-inflammatory enzymes, and a dominant anti-inflammatory environment in the spinal cord. These effects translate into reduced lesion volume in the spinal cord and greater functional blood flow after SCI. 


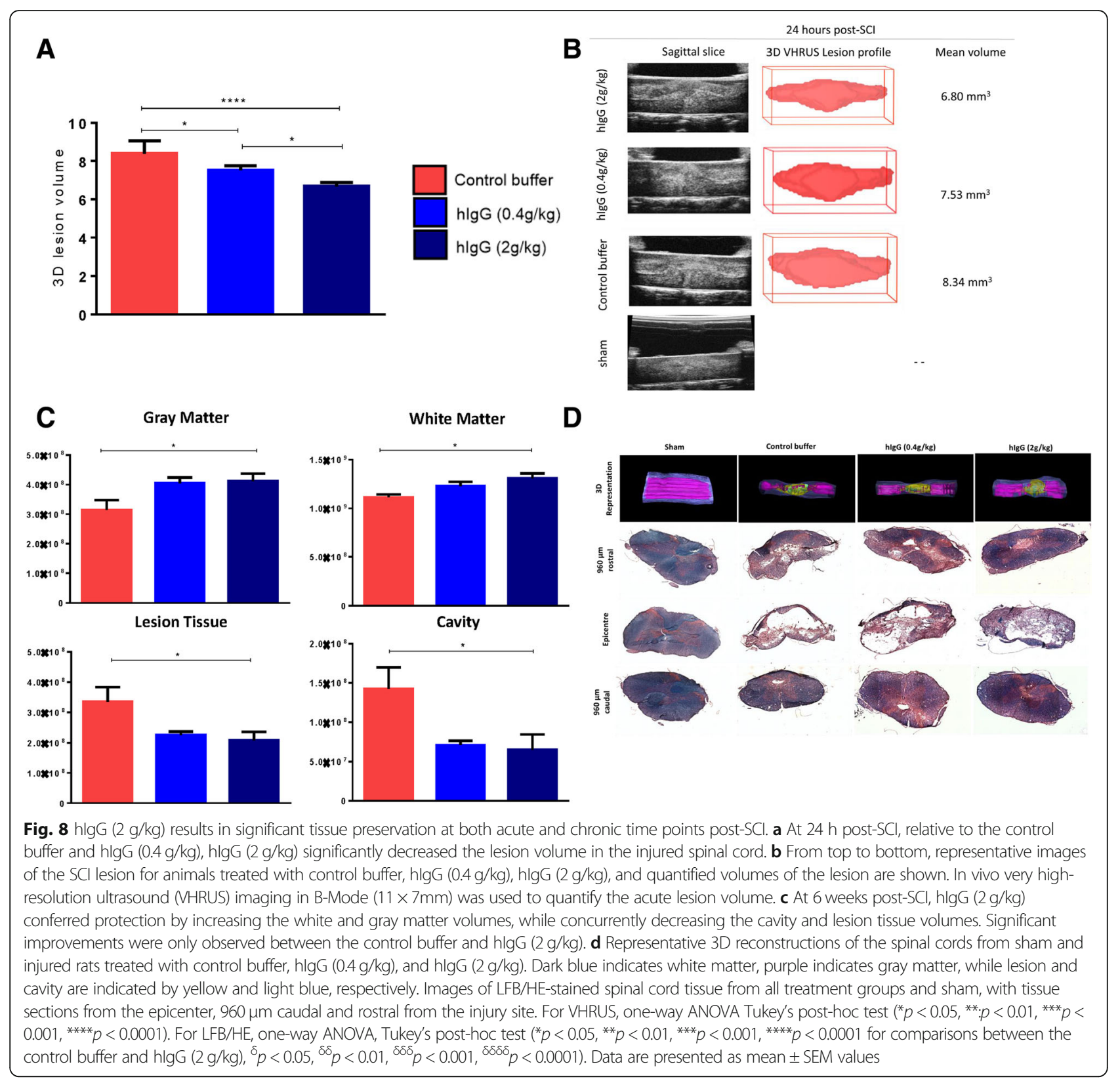

\section{High-dose hlgG for SCI treatment}

In the healthy CNS, an intact BSCB limits the entry of large molecules (such as human immunoglobulin G) [15, 30]. As such, the normal concentration of human immunoglobulin $\mathrm{G}$ in a steady-state cerebrospinal fluid/serum ratio is 0.0027 , with approximately 0.009 to $0.0017 \%$ of systemically administered immunoglobulin $\mathrm{G}$ reaching the healthy CNS. In the presence of CNS injury (i.e., SCI), a compromised BSCB allows human immunoglobulin $G$ to enter into the $\mathrm{CNS}$ at a significantly increased. Here, we show that hIgG $(2 \mathrm{~g} / \mathrm{kg})$ has significantly greater immunomodulatory effects than hIgG $(0.4 \mathrm{~g} / \mathrm{kg})$ to treat SCI. Importantly, high-dose hIgG $(2 \mathrm{~g} / \mathrm{kg})$ is used in other pre-clinical autoimmune disease models in both the peripheral and central systems, such as epilepsy [31], airway inflammation [32], chronic inflammatory demyelinating polyneuropathy [33], and idiopathic thrombocytopenic purpura [34].

\section{High-dose hlgG has effects on the spinal cord neurovascular unit}

hIgG was found to co-localize with various components of the rat $\mathrm{BSCB}$, such as astrocytes and pericytes, while accumulating in the vicinity of other components (blood vessels) and immune cells (microglia, neutrophils) of the spinal cord. Accumulation of hIgG due to the disrupted BSCB aligns with our previously published results [15]. 
The co-localization of hIgG on rat astrocytes and pericytes is of particular interest, as this suggests the ability of hIgG to modulate immune cell infiltration through the neurovascular unit [21]. Pericytes are an essential component of the BSCB and a sensor for neuroinflammatory signals produced by endothelial and parenchymal cells after CNS trauma $[35,36]$. Of the 3 components in the spinal cord neurovasculature unit (astrocytes, pericytes, and vessels), the integrity of the BSCB is primarily determined by the extent of MMP-9 expression in pericytes after the inflammatory response. MMP-9 expression causes pericytes to detach and migrate away from the basal lamina and, hence, results in BSCB disruption. The role of pericytes in maintaining the barrier integrity under healthy conditions is seen when pericyte-deficient mice demonstrate barrier breakdown and hypoperfusion [37]. Interestingly, we show that hIgG $(2 \mathrm{~g} / \mathrm{kg})$ significantly decreases MMP-9 expression. While the excessive proteolytic activity of MMPs is responsible for SCI pathophysiology, it should also be noted that MMP-9 activity is physiologically necessary for remodeling the extracellular matrix, tissue morphogenesis, and wound healing $[24,25]$.

An additional indicator of the protective effects of highdose hIgG on the neurovascular unit is the preservation of tight junction proteins, as indicated by higher protein levels of occludin and ZO-1 after high-dose hIgG treatment. A more durable BSCB is beneficial, as reducing vascular damage prevents immune cells from permeating into the injured spinal cord, which effectively limits the spread of secondary injury cascades [38]. In our model of clip compression-contusion $\mathrm{SCI}$, we have previously demonstrated that the BSCB is most disrupted at $24 \mathrm{~h}$ post-SCI and partially recovered by 2 weeks post-SCI. Importantly, this timeline corresponds with the period where there is a maximal MMP-9 activity, an enzyme whose biological substrates include multiple components of BSCB [24]. In the current paper, we provide evidence that hIgG $(2 \mathrm{~g} / \mathrm{kg})$ significantly reduces vascular permeability at a period of time post-SCI where the BSCB is most compromised. The greater integrity of the BSCB and improved functional vascularity are potential downstream effects of the interaction between hIgG and the spinal cord neurovascular unit, while also being associated with reduced active MMP-9 expression. As there is a positive correlation between BSCB integrity, functional vascularity, and behavioral/tissue recovery after SCI $[38,39]$, the neuroprotective interactions of hIgG-astrocytes-pericytes merit further investigation. Early repair of the BSCB has important implications for the treatment of SCI.

\section{High-dose hlgG has significant modulatory effects on immune cell populations after $\mathrm{SCl}$}

Neutrophils increase the extent of damage when entering into the injured tissue by binding to various adhesion molecules expressed on the inflamed endothelium, such as VCAM-1 [40]. Previous research has employed various methods to decrease neutrophil infiltration after $\mathrm{SCI}$, demonstrating both beneficial and harmful effects. Thus far, pre-clinical studies for SCI have used antibodies to block neutrophil entry [4, 5, 27, 41-43]. This highlights that strict immunosuppression can impede recovery, as it indiscriminately eliminates both beneficial and detrimental aspects of neuroinflammation. Our finding that hIgG significantly reduces neutrophil infiltration (using MPO assay and PMN stereology) is supported by previous publications [12, 15]. Reduced neutrophil infiltration, in combination with the observed improvements in BSCB integrity, suggests a feedforward protective loop. While a more intact BSCB can limit neutrophil infiltration, those neutrophils that successfully migrate into the inflamed tissue can continue to perform pathological effector functions [24]. Reduced neutrophil infiltration after hIgG $(2 \mathrm{~g} / \mathrm{kg})$ confers further protection by decreasing MMP-9 expression, effectively limiting leukocyte entry through the compromised BSCB. It is noteworthy that the ability of hIgG to reduce the expression of MMP-9 has been previously reported [44], but the mechanism is ill-defined. Furthermore, it was observed that hIgG co-localizes with VCAM-1, potentially suggesting that hIgG may impede the interactions between VCAM-1 and very late antigen-4 (VLA-4) [29], which would further limit neutrophil infiltration. Previous reports have demonstrated that blocking VLA-4 with monoclonal antibodies significantly reduces neutrophil infiltration in a mouse model of stroke and improves outcomes [45]. Furthermore, with in vitro inflammatory conditions, high-dose hIgG mediates immunomodulatory effects through interfering with leukocyte adhesion and rolling mechanisms [46, 47].

\section{High-dose hlgG modulates the inflammatory environment after spinal cord injury}

Here, we report a change in the expression of cytokines in the injured spinal cord after hIgG $(2 \mathrm{~g} / \mathrm{kg})$ treatment. Cytokines are the main orchestrators of the neuroinflammatory response, both of which are small families of proteins capable of recruiting and activating the aforementioned immune cells after SCI [48].

The ability of hIgG to promote an anti-inflammatory environment after SCI has been previously reported by our laboratory, as hIgG $(0.4 \mathrm{~g} / \mathrm{kg})$ has been shown to reduce inflammatory cytokines IL-1 $\beta$, IL-6, and monocyte chemoattractant protein-1 at $4 \mathrm{~h}$ post-SCI [15]. In the current study, we demonstrate that, relative to the control buffer, hIgG $(2 \mathrm{~g} / \mathrm{kg})$ increases protein expression of both inflammatory and anti-inflammatory cytokines. This phenomenon may be attributed to the administration of a high dose of an immunomodulatory molecule 
derived from an organism different from the host, which can elicit a modest immune response due to multiple mechanisms, such as the activation of complement system, receptor clustering and activation on innate immune effector cells, and recruitment of immune cells. Past studies have indicated that polymorphisms and interspecies differences of hIgG influence the binding of IgG to $\mathrm{Fc} \gamma$ receptors (FcyRs) and may alter the downstream signaling cascades $[49,50]$, a limitation of the current study that warrants further research. Nevertheless, the immune response elicited when administering an exogenous molecule can lead to greater expression of IL- 6 and TNF- $\alpha$ [51], a change observed in the current study. In vitro models indicate that hIgG can inhibit migration of neutrophils across endothelial cells stimulated with TNF- $\alpha$ and IL-1 $\beta$ [52], another phenomenon similar to what is reported in this manuscript. Reduction of neutrophil infiltration is also associated with decreased levels of neutrophil chemoattractants $\mathrm{CINC}-2 \alpha / \beta$ and CINC-3 after hIgG (2 g/kg) treatment [53].

Of note, the increased IL-1 $\beta$ after hIgG $(2 \mathrm{~g} / \mathrm{kg})$ treatment can bind to the immune cell receptors and activate the p38 pathway to enhance transcription and translation of multiple cytokines [54]. These include TNF- $\alpha$ and $\mathrm{CX}_{3} \mathrm{CL} 1$, both of which are highly expressed after hIgG $(2 \mathrm{~g} / \mathrm{kg})$ treatment. Importantly, the anti-inflammatory effects of hIgG $(2 \mathrm{~g} / \mathrm{kg})$, through increased IL-10 and $\mathrm{CX}_{3} \mathrm{CL1}$, can offset the inflammatory effects of IL- $1 \beta$ and TNF- $\alpha$ [55]. Furthermore, IL-10 favors a beneficial anti-inflammatory environment after neurotrauma by reducing MPO activity [56], edema, tissue damage, and apoptosis [57-59]. In regard to $\mathrm{CX}_{3} \mathrm{CL} 1$, it may exist in two forms and have different functions on immune cells expressing the corresponding receptor, $\mathrm{CX}_{3} \mathrm{CR} 1$ [60]. $\mathrm{CX}_{3} \mathrm{CL1}$ is expressed mainly by neurons but can also be expressed by astrocytes under inflammatory conditions. In its membrane-bound form, $\mathrm{CX}_{3} \mathrm{CL} 1$ is an adhesion molecule for $\mathrm{CX}_{3} \mathrm{CR}^{+}$cells. However, under excitotoxic conditions (such as $\mathrm{SCI}$ ), $\mathrm{CX}_{3} \mathrm{CL} 1$ can be cleaved into its soluble form, bind to $\mathrm{CX}_{3} \mathrm{CR} 1^{+}$cells, and maintain them in a quiescent state after injury [60-62]. As IL-10 can increase the levels of $\mathrm{CX}_{3} \mathrm{CR} 1 \mathrm{mRNA}$ [63], the greater levels of IL-10 may also mediate anti-inflammatory effects through a similar mechanism. Our findings of antiinflammatory effects, whether they are directly or indirectly caused by high-dose hIgG, align well with the past literature. These include many mechanisms, such as reduction of integrin activation, modulation of the expression and function of FcyRs, neutralization of autoantibodies, regulation of cell proliferation, interference with activation of the complement cascade, and modulation of the cytokine network [10, 64].

In stark contrast, the administration of hIgG $(2 \mathrm{~g} / \mathrm{kg})$ significantly upregulated multiple pro-inflammatory cytokines in sera after SCI, a phenomenon that has been reported in patients with immune disorders [65-67]. Here, we report that hIgG $(2 \mathrm{~g} / \mathrm{kg})$ increased serum protein expression of neutrophil chemoattractants (IL-8, MIP-1 $\alpha$, CCL-2/MCP-1) and eosinophil activator (IL-5). Notably, pro-inflammatory cytokines are expectedly downregulated after MPSS $(0.03 \mathrm{~g} / \mathrm{kg})$ treatment [68]. As SCI patients experience systemic immune deficiency [7], the ability of hIgG to enhance pro-inflammatory mediators may dampen the severity of immune suppression by mobilizing innate and adaptive immune cell populations that are reduced in pre-clinical models of SCI and SCI patients $[7,69]$. Changes in cytokine secretion and immune cell effector functions correspond to alterations mediated by $\mathrm{F}_{\mathrm{c}}$ and $\mathrm{F}_{(\mathrm{ab}) 2}$ components of $\operatorname{hIgG}[70,71]$. Specifically, the increase in inflammatory cytokines may traffic immune cells to the spleen, a major immune cell reservoir/source that's role in SCI pathophysiology has gained increased attention recently [72]. Neutrophils are found in the rat spleen and active after SCI [73, 74]. As hIgG $(2 \mathrm{~g} / \mathrm{kg})$ alleviates neutrophil infiltration in the spinal cord and increases splenic weight, the increased levels of neutrophil chemoattractants may redirect neutrophils to the spleen. Future studies are needed to evaluate how hIgG modulates splenic immune cell populations after SCI.

\section{High-dose hlgG significantly increases tissue preservation and functional recovery after $\mathrm{SCl}$}

Tissue preservation and neural repair after SCI are important, as the spinal cord is a complex structure with a large number of ascending and descending neural tracts that connect specific brain structures to precise locations in the body. In this study, we extend our previous findings, as well as others $[12,13,15]$, by showing that hIgG $(2 \mathrm{~g} / \mathrm{kg})$ results in significantly more potent immunomodulatory effects as mediated by acute molecular and biochemical changes. This translates into better functional recovery and tissue preservation at both acute and chronic time points post-SCI. As enhancing the survival of $5-10 \%$ of the fibers at the lesion center of the spinal cord helps drive the segmental circuits involved in the production of basic locomotion [75], relatively small improvements in neuroanatomical integrity after SCI can have a substantial, clinically relevant impact on neurological recovery and greatly reduce patient morbidity.

\section{Conclusion}

Extensive pre-clinical and clinical evidence has shown that hIgG therapy is safe, and adverse effects associated with its administration are mild and transient. Although MPSS is the only pharmaceutical neuroprotective therapy currently used for SCI in the clinic, it is potentially suboptimal due to the systemic immune deficiency 
exhibited by SCI patients and the dual nature of the acute inflammatory response. In the current paper, we show that high-dose hIgG is an easily deliverable therapeutic at the acute stage of SCI, and the neuroprotective effect is mediated, in part, by preserving BSCB integrity. This attenuates immune cell infiltration, promotes an anti-inflammatory environment, and enhances tissue preservation and functional recovery after injury. However, before hIgG can be used in the clinic to treat SCI, further optimization of efficacy and delineating its mechanism are required. This may include studying more clinically relevant time points to administer hIgG as well as determining which component of the hIgG molecule mediates the observed immunomodulatory effects. Overall, our study supports the growing trend of using immunomodulatory, rather than immunosuppressive, strategies to treat SCI.

\begin{abstract}
Abbreviations
ANOVA: Analysis of variance; BBB: Beattie-Basso-Bresnahan; BSCB: Bloodspinal cord barrier; $\mathrm{CX}_{3} \mathrm{CL}$ 1: Fractalkine; $\mathrm{CX}_{3} \mathrm{CR} 1$ : Fractalkine receptor; FcyR: Fcy receptor; hlgG: Human immunoglobulin G; HRP: Horseradish peroxidase; Iba-1: Ionized calcium-binding adapter molecule-1; IL: Interleukin; LFB/HE: Luxol fast blue/hematoxylin and eosin; MMP-9: Matrix metalloproteinase-9; MPO: Myeloperoxidase; MPSS: Methylprednisolone; mRNA: Messenger ribonucleic acid; PBS: Phosphate-buffered saline; SCI: Spinal cord injury; SEM: Standard error of mean; T-BST: Tris-buffered saline with $0.2 \%$ Tween; TJ: Tight junction; VCAM-1: Vascular cellular adhesion molecule-1; VEGF: Vascular endothelial growth factor; VHRUS: Very highresolution ultrasound; ZO-1: Zonula occludens-1
\end{abstract}

\section{Acknowledgements}

The authors gratefully acknowledge Mahmood Chamankhah for optimizing the western blot as well as all members of the Fehlings laboratory for their dedication and support.

\section{Authors' contributions}

JC contributed to the conception and design, surgeries, collection/assembly of data, data analysis and interpretation, manuscript writing. JW contributed to the surgeries and collection/assembly of data. AB contributed to the collection/assembly of data, data analysis, and manuscript editing. JH contributed to the collection/assembly of data and data analysis. VS contributed to the collection/assembly of data and data analysis. MF contributed to the conception and design, data interpretation, financial support, and manuscript editing. All authors read and approved the final manuscript.

\section{Funding}

Baxter Healthcare Corporation is responsible for providing material support through the Baxter BioScience Grant. Michael Fehlings holds the Gerald and Tootsie Halbert Chair in Neural Repair and Regeneration. Jonathon Chio holds the Frederick Banting and Charles Best Graduate Scholarship.

\section{Availability of data and materials}

The datasets used and/or analyzed during the current study are available from the corresponding author on reasonable request.

\section{Ethics approval and consent to participate}

All animal experiments were approved by the animal care committee at the University Health Network (Toronto, Ontario, Canada) in compliance with the Canadian Council on Animal Care.

\section{Consent for publication}

Not applicable.

\section{Competing interests}

The authors declare that they have no competing interests.

\section{Author details}

${ }^{1}$ Department of Genetics and Development, Krembil Research Institute, University Health Network, Krembil Discovery Tower, 60 Leonard Avenue, 7KD-430, Toronto, Ontario M5T 258, Canada. ${ }^{2}$ Institute of Medical Science, University of Toronto, Toronto, Ontario, Canada. ${ }^{3}$ Sue and Bill Gross Stem Cell Research Centre, University of California, 845 Health Sciences Road, Irvine, CA 92617, USA. ${ }^{4}$ Spinal Program, Toronto Western Hospital, University Health Network, Toronto, Ontario, Canada. ${ }^{5}$ University of Toronto, Toronto, Ontario, Canada. ${ }^{6}$ Gerry and Tootsie Halbert Chair in Neural Repair and Regeneration, University of Toronto, Toronto, Canada. ${ }^{7}$ Krembil Neuroscience Program, Toronto Western Hospital, University Health Network, 399 Bathurst Street, Toronto, Ontario M5T 2S8, Canada.

Received: 27 November 2018 Accepted: 11 June 2019

Published online: 09 July 2019

References

1. Kjell, J. \& Olson, L. Rat models of spinal cord injury: from pathology to potential therapies. 9, 1125-1137 (2016).

2. Taoka Y, et al. Role of neutrophils in spinal cord injury in the rat. Neuroscience. 1997:79:1177-82

3. Popovich PG, et al. Depletion of hematogenous macrophages promotes partial hindlimb recovery and neuroanatomical repair after experimental spinal cord injury. Exp Neurol. 1999;158:351-65. https://doi.org/10.1006/exnr. 1999.7118.

4. Bao F, Chen Y, Dekaban GA, Weaver LC. Early anti-inflammatory treatment reduces lipid peroxidation and protein nitration after spinal cord injury in rats. J Neurochem. 2004:88:1335-44.

5. Gris D, et al. Transient blockade of the CD11d/CD18 integrin reduces secondary damage after spinal cord injury, improving sensory, autonomic, and motor function. J Neurosci. 2004;24:4043-51. https://doi.org/10.1523/ jneurosci.5343-03.2004.

6. Baptiste DC, Fehlings MG. Pharmacological approaches to repair the injured spinal cord. J Neurotrauma. 2006;23:318-34. https://doi.org/10.1089/neu. 2006.23.318

7. Riegger $T$, et al. Spinal cord injury-induced immune depression syndrome (SCI-IDS). Eur J Neurosci. 2007;25:1743-7. https://doi.org/10.1111/j.1460-9568. 2007.05447.x.

8. Brommer B, et al. Spinal cord injury-induced immune deficiency syndrome enhances infection susceptibility dependent on lesion level. Brain: a Journal of Neurology. 2016. https://doi.org/10.1093/brain/awv375.

9. Goldstein EZ, Church JS, Hesp ZC, Popovich PG, McTigue DM. A silver lining of neuroinflammation: beneficial effects on myelination. Exp Neurol. 2016. https://doi.org/10.1016/j.expneurol.2016.05.001.

10. Nimmerjahn F, Ravetch JV. Anti-inflammatory actions of intravenous immunoglobulin. Annu Rev Immunol. 2008;26:513-33. https://doi.org/10. 1146/annurev.immunol.26.021607.090232.

11. Tzekou A, Fehlings MG. Treatment of spinal cord injury with intravenous immunoglobulin G: preliminary evidence and future perspectives. J Clin Immunol. 2014;34(Suppl 1):S132-8. https://doi.org/10 1007/s10875-014-0021-8.

12. Gok B, et al. Immunomodulation of acute experimental spinal cord injury with human immunoglobulin G. Journal of Clinical Neuroscience: official journal of the Neurosurgical Society of Australasia. 2009;16:549-53. https:// doi.org/10.1016/j.jocn.2008.04.024

13. Brennan $\mathrm{FH}$, et al. IVIg attenuates complement and improves spinal cord injury outcomes in mice. Annals of Clinical and Translational Neurology, n/ a-n/a. 2016. https://doi.org/10.1002/acn3.318.

14. Sroga JM, Jones TB, Kigerl KA, McGaughy VM, Popovich PG. Rats and mice exhibit distinct inflammatory reactions after spinal cord injury. J Comp Neurol. 2003;462:223-40. https://doi.org/10.1002/cne.10736.

15. Nguyen $\mathrm{DH}$, et al. Immunoglobulin $\mathrm{G}(\mathrm{lgG})$ attenuates neuroinflammation and improves neurobehavioral recovery after cervical spinal cord injury. J Neuroinflammation. 2012:9:224. https://doi.org/10.1186/1742-2094-9-224.

16. Rivlin AS, Tator $\mathrm{CH}$. Objective clinical assessment of motor function after experimental spinal cord injury in the rat. J Neurosurg. 1977;47:577-81. https://doi.org/10.3171/jns.1977.47.4.0577. 
17. Fehlings $\mathrm{MG}$, Tator $\mathrm{CH}$. The relationships among the severity of spinal cord injury, residual neurological function, axon counts, and counts of retrogradely labeled neurons after experimental spinal cord injury. Exp Neurol. 1995;132:220-8.

18. Bracken $M B$, et al. Administration of methylprednisolone for 24 or 48 hours or tirilazad mesylate for 48 hours in the treatment of acute spinal cord injury. Results of the third National Acute Spinal Cord Injury Randomized Controlled Trial. National Acute Spinal Cord Injury Study. Jama. 1997;277:1597-604.

19. Soubeyrand M, Badner A, Vawda R, Chung YS, Fehlings MG. Very high resolution ultrasound imaging for real-time quantitative visualization of vascular disruption after spinal cord injury. J Neurotrauma. 2014;31:1767-75. https://doi.org/10.1089/neu.2013.3319.

20. Wilcox JT, Satkunendrarajah K, Zuccato JA, Nassiri F, Fehlings MG. Neural precursor cell transplantation enhances functional recovery and reduces astrogliosis in bilateral compressive/contusive cervical spinal cord injury. Stem Cells Transl Med. 2014;3:1148-59. https://doi.org/10.5966/sctm.2014-0029.

21. Zozulya A, Weidenfeller C, Galla HJ. Pericyte-endothelial cell interaction increases MMP-9 secretion at the blood-brain barrier in vitro. Brain Res. 2008;1189:1-11. https://doi.org/10.1016/j.brainres.2007.10.099.

22. Donnelly DJ, Popovich PG. Inflammation and its role in neuroprotection, axonal regeneration and functional recovery after spinal cord injury. Exp Neurol. 2008;209:378-88. https://doi.org/10.1016/j.expneurol.2007.06.009.

23. He $Z$, et al. Inhibiting endoplasmic reticulum stress by lithium chloride contributes to the integrity of blood-spinal cord barrier and functional recovery after spinal cord injury. Am J Transl Res. 2017;9:1012-24.

24. Noble LJ, Donovan F, Igarashi T, Goussev S, Werb Z. Matrix metalloproteinases limit functional recovery after spinal cord injury by modulation of early vascular events. J Neurosci. 2002;22:7526-35.

25. Vandooren J, Van den Steen PE, Opdenakker G. Biochemistry and molecular biology of gelatinase B or matrix metalloproteinase-9 (MMP-9): the next decade. Crit Rev Biochem Mol Biol. 2013;48:222-72. https://doi.org/10.3109/ 10409238.2013.770819.

26. de Castro RC Jr, Burns CL, McAdoo DJ, Romanic AM. Metalloproteinase increases in the injured rat spinal cord. Neuroreport. 2000;11:3551-4.

27. Stirling DP, Liu S, Kubes P, Yong WW. Depletion of Ly6G/gr-1 leukocytes after spinal cord injury in mice alters wound healing and worsens neurological outcome. J Neurosci. 2009;29:753-64. https://doi.org/10.1523/jneurosci.491808.2009.

28. Zhang $Y$, et al. Autonomic dysreflexia causes chronic immune suppression after spinal cord injury. J Neurosci. 2013;33:12970-81. https://doi.org/10. 1523/jneurosci.1974-13.2013.

29. Neumann J, et al. Very-late-antigen-4 (VLA-4)-mediated brain invasion by neutrophils leads to interactions with microglia, increased ischemic injury and impaired behavior in experimental stroke. Acta Neuropathol. 2015;129: 259-77. https://doi.org/10.1007/s00401-014-1355-2.

30. St-Amour I, et al. Brain bioavailability of human intravenous immunoglobulin and its transport through the murine blood-brain barrier. Journal of Cerebral Blood Flow and Metabolism: official Journal of the International Society of Cerebral Blood Flow and Metabolism. 2013;33:198392. https://doi.org/10.1038/jcbfm.2013.160.

31. Chen $\mathrm{M}$, et al. Disease-modifying effect of intravenous immunoglobulin in an experimental model of epilepsy. Sci Rep. 2017;7:40528. https://doi.org/10. 1038/srep40528.

32. Massoud AH, et al. Dendritic cell immunoreceptor: a novel receptor for intravenous immunoglobulin mediates induction of regulatory $T$ cells. J Allergy Clin Immunol. 2014;133:853-863.e855. https://doi.org/10.1016/j.jaci. 2013.09.029

33. Tackenberg B, et al. Impaired inhibitory Fcgamma receptor IIB expression on B cells in chronic inflammatory demyelinating polyneuropathy. Proc Nat Acad Sci U S A. 2009;106:4788-92. https://doi.org/10.1073/pnas.0807319106.

34. Crow AR, et al. IVIg-mediated amelioration of murine ITP via FcgammaRIIB is independent of SHIP1, SHP-1, and Btk activity. Blood. 2003;102:558-60. https://doi.org/10.1182/blood-2003-01-0023.

35. Takata F, et al. Brain pericytes among cells constituting the blood-brain barrier are highly sensitive to tumor necrosis factor-alpha, releasing matrix metalloproteinase-9 and migrating in vitro. J Neuroinflammation. 2011;8: 106. https://doi.org/10.1186/1742-2094-8-106.

36. Goritz C, et al. A pericyte origin of spinal cord scar tissue. Science (New York, NY). 2011;333:238-42. https://doi.org/10.1126/science.1203165.

37. Armulik $A$, et al. Pericytes regulate the blood-brain barrier. Nature. 2010:468: 557-61. https://doi.org/10.1038/nature09522.
38. Figley SA, Khosravi R, Legasto JM, Tseng YF, Fehlings MG. Characterization of vascular disruption and blood-spinal cord barrier permeability following traumatic spinal cord injury. J Neurotrauma. 2014;31:541-52. https://doi.org/ 10.1089/neu.2013.3034.

39. Badner A, et al. Early intravenous delivery of human brain stromal cells modulates systemic inflammation and leads to vasoprotection in traumatic spinal cord injury. Stem Cells Transl Med. 2016;5:991-1003. https://doi.org/ 10.5966/sctm.2015-0295

40. Bowes AL, Yip PK. Modulating inflammatory cell responses to spinal cord injury: all in good time. J Neurotrauma. 2014;31:1753-66. https://doi.org/10. 1089/neu.2014.3429.

41. Ditor DS, Bao F, Chen Y, Dekaban GA, Weaver LC. A therapeutic time window for anti-CD 11d monoclonal antibody treatment yielding reduced secondary tissue damage and enhanced behavioral recovery following severe spinal cord injury. Journal of Neurosurgery Spine. 2006:5:343-52. https://doi.org/10.3171/spi.2006.5.4.343.

42. Bao F, Omana $V$, Brown A, Weaver LC. The systemic inflammatory response after spinal cord injury in the rat is decreased by alpha4beta1 integrin blockade. J Neurotrauma. 2012;29:1626-37. https://doi.org/10.1089/neu.2011.2190.

43. Bao F, Brown A, Dekaban GA, Omana V, Weaver LC. CD11d integrin blockade reduces the systemic inflammatory response syndrome after spinal cord injury. Exp Neurol. 2011;231:272-83. https://doi.org/10.1016/j. expneurol.2011.07.001

44. Dalakas MC. Mechanisms of action of IVlg and therapeutic considerations in the treatment of acute and chronic demyelinating neuropathies. Neurology. 2002:59:S13-21.

45. Liesz A, et al. Inhibition of lymphocyte trafficking shields the brain against deleterious neuroinflammation after stroke. Brain: a Journal of Neurology. 2011;134:704-20. https://doi.org/10.1093/brain/awr008.

46. Macmillan HF, Rowter D, Lee T, Issekutz AC. Intravenous immunoglobulin G selectively inhibits IL-1alpha-induced neutrophil-endothelial cell adhesion. Autoimmunity. 2010;43:619-27. https://doi.org/10.3109/08916931003599062.

47. Gill V, Doig C, Knight D, Love E, Kubes P. Targeting adhesion molecules as a potential mechanism of action for intravenous immunoglobulin. Circulation. 2005;112:2031-9. https://doi.org/10.1161/circulationaha.105.546150.

48. Kabu S, Gao Y, Kwon BK, Labhasetwar V. Drug delivery, cell-based therapies, and tissue engineering approaches for spinal cord injury. Journal of Controlled Release: official Journal of the Controlled Release Society. 2015. https://doi.org/10.1016/j.jconrel.2015.08.060.

49. Trist $\mathrm{HM}$, et al. Polymorphisms and interspecies differences of the activating and inhibitory FcgammaRII of Macaca nemestrina influence the binding of human IgG subclasses. Journal of Immunology (Baltimore, Md: 1950). 2014; 192:792-803. https://doi.org/10.4049/jimmunol.1301554.

50. Tjon AS, van Gent R, Geijtenbeek TB, Kwekkeboom J. Differences in antiinflammatory actions of intravenous immunoglobulin between mice and men: more than meets the eye. Front Immunol. 2015;6:197. https://doi.org/ 10.3389/fimmu.2015.00197.

51. Guo Y, Tian X, Wang X, Xiao Z. Adverse effects of immunoglobulin therapy. Front Immunol. 2018;9:1299. https://doi.org/10.3389/fimmu.2018.01299.

52. Issekutz AC, Rowter D, Macmillan HF. Intravenous immunoglobulin G (IVIG) inhibits IL-1- and TNF-alpha-dependent, but not chemotactic-factorstimulated, neutrophil transendothelial migration. Clinical Immunology (Orlando, Fla). 2011;141:187-96. https://doi.org/10.1016/j.clim.2011.08.003.

53. Morimoto $Y$, et al. Expression of cytokine-induced neutrophil chemoattractant in rat lungs following an intratracheal instillation of micron-sized nickel oxide nanoparticle agglomerates. Toxicol Ind Health. 2014;30:851-60. https://doi.org/10.1177/0748233712464807.

54. Chakraborty S, Kaushik DK, Gupta M, Basu A. Inflammasome signaling at the heart of central nervous system pathology. J Neurosci Res. 2010;88:1615-31. https://doi.org/10.1002/jnr.22343.

55. Ballow M. The lgG molecule as a biological immune response modifier: mechanisms of action of intravenous immune serum globulin in autoimmune and inflammatory disorders. J Allergy Clin Immunol. 2011;127: 315-23; quiz 324-315. https://doi.org/10.1016/j.jaci.2010.10.030.

56. Thompson CD, Zurko JC, Hanna BF, Hellenbrand DJ, Hanna A. The therapeutic role of interleukin-10 after spinal cord injury. J Neurotrauma. 2013;30:1311-24. https://doi.org/10.1089/neu.2012.2651.

57. Genovese T, et al. Absence of endogenous interleukin-10 enhances secondary inflammatory process after spinal cord compression injury in mice. J Neurochem. 2009;108:1360-72. https://doi.org/10.1111/j.1471-4159. 2009.05899.x 
58. Abraham KE, McMillen D, Brewer KL. The effects of endogenous interleukin10 on gray matter damage and the development of pain behaviors following excitotoxic spinal cord injury in the mouse. Neuroscience. 2004; 124:945-52. https://doi.org/10.1016/..neuroscience.2004.01.004.

59. Badner A, Vidal PM, Hong J, Hacker J, Fehlings MG. Endogenous Interleukin10 deficiency exacerbates vascular pathology in traumatic cervical spinal cord injury. J Neurotrauma. 2019. https://doi.org/10.1089/neu.2018.6081.

60. Lyons $\mathrm{A}$, et al. Fractalkine-induced activation of the phosphatidylinositol-3 kinase pathway attentuates microglial activation in vivo and in vitro. J Neurochem. 2009;110:1547-56. https:/doi.org/10.1111/j.1471-4159.2009.06253.x.

61. Noda $\mathrm{M}$, et al. Fractalkine attenuates excito-neurotoxicity via microglial clearance of damaged neurons and antioxidant enzyme heme oxygenase-1 expression. J Biol Chem. 2011;286:2308-19. https://doi.org/10.1074/jbc.M110.169839.

62. Paolicelli RC, Bisht K, Tremblay ME. Fractalkine regulation of microglial physiology and consequences on the brain and behavior. Front Cell Neurosci. 2014;8:129. https://doi.org/10.3389/fncel.2014.00129.

63. Yano $R$, et al. Recruitment of CD16+ monocytes into synovial tissues is mediated by fractalkine and CX3CR1 in rheumatoid arthritis patients. Acta Med Okayama. 2007;61:89-98.

64. Durandy A, et al. Intravenous immunoglobulins--understanding properties and mechanisms. Clin Exp Immunol. 2009;158 Suppl 1, 2-13. https://doi.org/ 10.1111/j.1365-2249.2009.04022.x.

65. Kudo $H$, et al. Intravenous immunoglobulin treatment recovers the downregulated levels of Th1 cytokines in the sera and skin of scleroderma patients. J Dermatol Sci. 2013;69:77-80. https://doi.org/10.1016/j.jdermsci. 2012.09.010

66. Kuo HC, et al. Association of lower eosinophil-related Thelper 2 (Th2) cytokines with coronary artery lesions in Kawasaki disease. Pediatric Allergy and Immunology: Official Publication of the European Society of Pediatric Allergy and Immunology. 2009;20:266-72. https://doi.org/10.1111/j.13993038.2008.00779.x.

67. Sewell WA, Jolles S. Immunomodulatory action of intravenous immunoglobulin. Immunology. 2002;107:387-93.

68. Fu ES, Saporta S. Methylprednisolone inhibits production of interleukin1 beta and interleukin-6 in the spinal cord following compression injury in rats. J Neurosurg Anesthesiol. 2005;17:82-5.

69. Riegger T, et al. Immune depression syndrome following human spinal cord injury (SCI): a pilot study. Neuroscience. 2009;158:1194-9. https://doi.org/10. 1016/j.neuroscience.2008.08.021.

70. Matsuda A, et al. Anti-inflammatory effects of high-dose lgG on TNF-alphaactivated human coronary artery endothelial cells. Eur J Immunol. 2012;42: 2121-31. https://doi.org/10.1002/eji.201242398.

71. Nimmerjahn F. Translating inhibitory fc receptor biology into novel therapeutic approaches. J Clin Immunol. 2016;36(Suppl 1):83-7. https://doi. org/10.1007/s10875-016-0249-6

72. Ueno M, Ueno-Nakamura Y, Niehaus J, Popovich PG, Yoshida Y. Silencing spinal interneurons inhibits immune suppressive autonomic reflexes caused by spinal cord injury. Nat Neurosci. 2016. https://doi.org/10.1038/nn.4289.

73. Ulndreaj A, et al. Characterization of the antibody response after cervical spinal cord injury. J Neurotrauma. 2016. https://doi.org/10.1089/neu.2016.4498.

74. Swirski FK, et al. Identification of splenic reservoir monocytes and their deployment to inflammatory sites. Science (New York, NY). 2009;325:612-6. https://doi.org/10.1126/science.1175202.

75. Cheng P, Kuang F, Zhang H, Ju G, Wang J. Beneficial effects of thymosin beta4 on spinal cord injury in the rat. Neuropharmacology. 2014;85:408-16. https://doi.org/10.1016/j.neuropharm.2014.06.004.

\section{Publisher's Note}

Springer Nature remains neutral with regard to jurisdictional claims in published maps and institutional affiliations.

Ready to submit your research? Choose BMC and benefit from:

- fast, convenient online submission

- thorough peer review by experienced researchers in your field

- rapid publication on acceptance

- support for research data, including large and complex data types

- gold Open Access which fosters wider collaboration and increased citations

- maximum visibility for your research: over $100 \mathrm{M}$ website views per year

At BMC, research is always in progress.

Learn more biomedcentral.com/submissions 